Portland State University

PDXScholar

$1-1-1983$

\title{
Short-term wellness program for a school staff comparing levels of support
}

Wynferd Ray Chilton

Portland State University

Follow this and additional works at: https://pdxscholar.library.pdx.edu/open_access_etds Let us know how access to this document benefits you.

\section{Recommended Citation}

Chilton, Wynferd Ray, "Short-term wellness program for a school staff comparing levels of support" (1983). Dissertations and Theses. Paper 873.

https://doi.org/10.15760/etd.873

This Dissertation is brought to you for free and open access. It has been accepted for inclusion in Dissertations and Theses by an authorized administrator of PDXScholar. Please contact us if we can make this document more accessible: pdxscholar@pdx.edu. 
SHORT-TERM WELLNESS

PROGRAM FOR A SCHOOL STAFF

COMPARING LEVELS GE SUPPORT

\author{
by \\ WYNFERD RAY CHILTON
}

A dissertation submitted in partial fulfillment of the requirements for the degree of

DOCTOR OF EDUCATION
in
PUBLIC SCHOOL ADMINISTRATION AND SUPERVISION

Portland State University

1983 
TO THE OFFICE OF GRADUATE STUDIES AND RESEARCH:

The members of the Committee approve the dissertation of Wynferd Ray Chilton presented May 19,1983.

\section{John Lind, Cha i rpelrson}

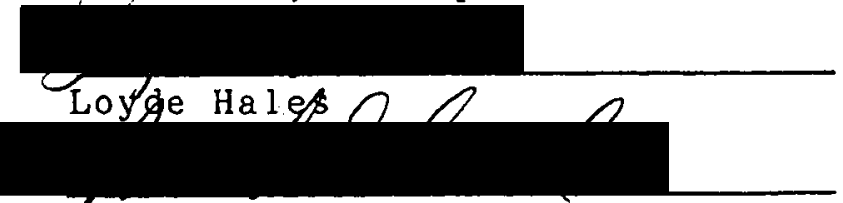

Mi chael Carl
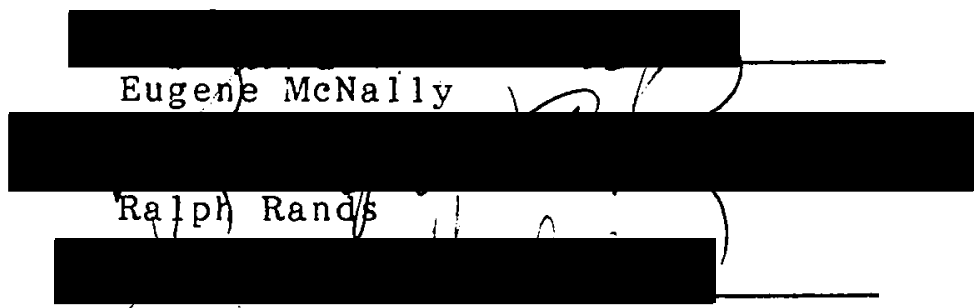

Gerald Guthrie

APPROVED :

George v, Guy, Bi-University Program Coordinator (Portland

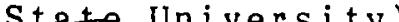

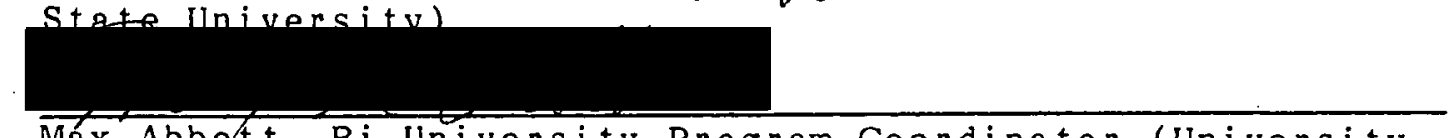

Max Abbot, Bi-University Program Coordinator (University of Oregon)

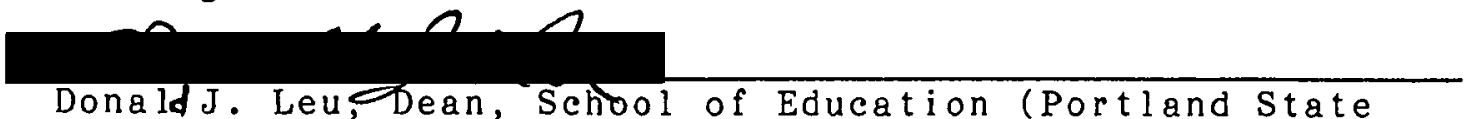

DonaldJ. Leu, Dean, School of Education (Portland State University)

Stanley Rauch, Dean, Graduate Studies and Research

(Portland State University) 
AN ABSTRACT OF THE DISSERTATION OF Wynferd Ray Chilton for the Doctor of Education in Public School Administration and Supervision presented May 19,1983

Title: Short Term Wellness Program for a School Staff Comparing Levels of Support

APPROVED BY MEMBERS OF THE DISSERTATION COMMITTEE:

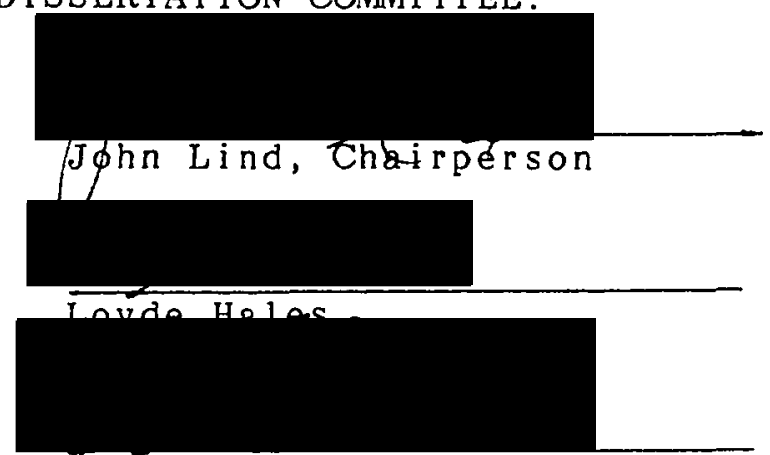

Wichael Carl
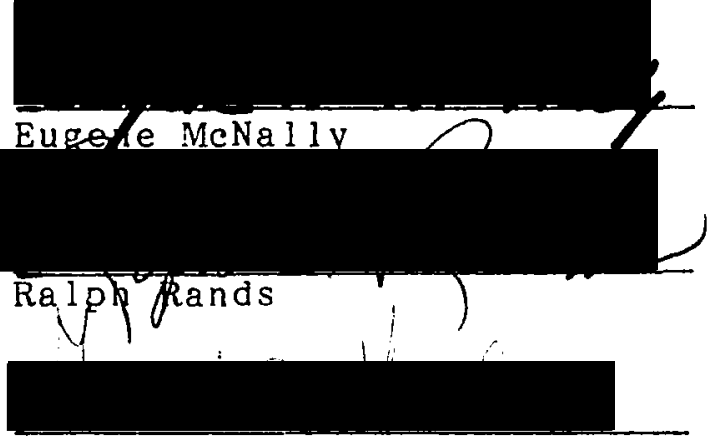

Gerald Guthrie

. This study conducted an experiment with 139 staff volunteers from a suburban school district $(K-12)$ who participated in a eight-week program of exercise, nutritional practices, and stress control measures. All participants were pretested and posttested for mental well-being 
and physical fitness. Two treatment groups set goals, wrote contracts, and met weekly to hear speakers and share experiences, and made weekly reports to a director of the project. One treatment group was provided with leaders who organized supporting activities; the other treatment group were divided into support groups without leaders. A third group was composed of individuals who did not participate in the formal program but were present in the schools where general wellness activities may have affected their health-related activities.

The program produced significant changes in mental and physical health, whereas the informal influences on the third group produced no significant change in physical fitness but did, to a lesser degree, produce a significant change in the mental health of it members. Significant relationships were found between the level of healthrelated behavior sustained in the program and changes in mental and physical health; physical health levels and improvement were not found to be related to mental health levels or improvement. The levels of support produced significant results only when comparing treatment groups with the third group (that did not participate in the formal program); leader-led groups did not produced significantly different results from the leaderless groups.

The description of the wellness program and the results of its use provide a model for school administrators 
who wish to improve the health and productivity of their staff. It also represents a method of introducing wellness into the school curriculum. Staff members become models for wellness and enthusiasts for the benefits of such programs. 


\section{ACKNOWLEDGEMENTS}

There were 1 iterally hundreds of people who helped with this project to whom I am most grateful. There were the participants - the 150 or more staff members of the Gresham schools who exercised, dieted, and reported their behavior to me for eight weeks. There were the health teachers, PE teachers, and nurses of the districts who helped me set up testing centers and gave physical fitness tests to nearly 200 people (twice). There were the health experts who gave direction and advice -- Len Tritsch, State Department of Eduction; Don Hall and Harold Burden, Portland Advent ist Medical Center; and Jeff Rhoem, Mt. Hood Community College.

There were the members of my dissertation committee to whom I give thanks for their time and advice, especially Dr. John Lind (chairperson) and Dr. Loyde Hales.

There was my wife, Judy, who did all of the above and more. 
TABLE OF CONTENTS

PAGE

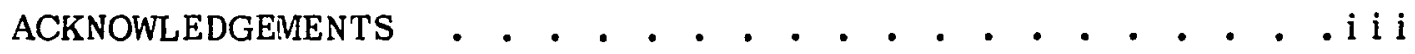

LIST OF TABLES • . . . . . . . . . . . . . . . . vi

CHAPTER

I . INTRODUCT ION

Recent Changes in Health Problems and Solutions . . . . . . . . . . . . 1 Implication for the Public School System. 9 Statement of the Problem . . . . . . . . 12 Scope and Methods of this study . . . . . 12 Importance of the Study . . . . . . . . . 14

I I REVIEW OF THE LITERATURE

Health Promotion . . . . . . . . . 16 Integrated Versus Single Factor Programs. . 21 Institutional Help Versus Self Help... 28 Developmental Levels of Behavioral

Change Programs... . . . . . . . . 30

Focus on Short-Term Behavioral Change: $: 32$

Value of Support Systems in

Changing Behavior . . . . . . . . . 36

Summary of the Literature Review . . . . 44

I I I. METHODS AND PROCEDURES

Description of the Wellness Program... . 47

Measurement of Dependent Variables . . . . 53

Statistical Treatment of Data . . . . . 58

IV. RESULTS AND ANALYSIS

Pre-Treatment Characteristics of the

Sample Groups . . . . . . . . . 60

Assessment of Health . . . . . . . . . 68

Health-Related Behavior Reported by

Participants . . . . . . . . . . 72

Improvement of Physical and Mental Health Factors ........... . 79

Correlation of Physical and Mental

Health Factors............ . 81

Comparison of Post-Treatment Levels of

Group Means . . . . . . . 85 
V. GENERALIZATIONS, RECOMMENDATIONS, AND

FURTHER STUDY

Summary of the Study and Results . . . . 87

Patterns Among Test Results

Further Study . . . . . . . . . . . . 100

REFERENCE NOTES $\quad$. . . . . . . . . . . . . 103

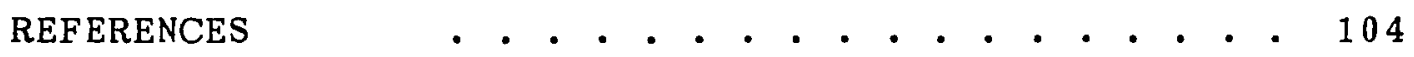

APPENDICES $\quad$. . . . . . . . . . . . . . . 108 


\section{LIST OF TABLES}

TABLE

PAGE

I Comparison of Demographic Characteristics of Gresham School's Staff and Wellness

Class Participants............ 61

I I Comparison of Demographic Characteristics of Treatment and Control Groups of Gresham

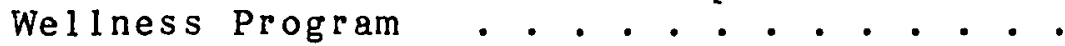

II Dropouts from Gresham School's Wellness Program . . . . . . . . . . . . . .

IV Comparison of Demographic and Pre-Treatment Characteristics of Treatment and Control Groups of Gresham Weliness Program . . . .

$V$ Percentages of Treatment and Control Groups Following Recommended Nutritional Practices Prior to Wellness Program .........

VI Composition of Treatment Groups and Control Group in Levels of Well-Being Before and After the Gresham Wellness Program . . . . 71

VII Composition of Treatment Groups and Control Group in Levels of Physical Fitness Before and After the Gresham Program

VIII Self-Reported Levels of Participation in Wellness Behaviors by Treatment Groups in Gresham Program . . . . . . . . . . .

IX Types of Physical Exercise and Relative Frequency Reported by Participants in Gresham Wellness Program . . . . . . . . . . . 75

$X$ Barriers and Resources to Maintaining Individual Contracts Reported by Participants in Gresham Wellness Program . . . . . . . 77

XI $t$-Test Comparison of Pre-Treatment and PostTreatment Means of Physical and Mental WellBeing Scores of Wellness Group . . . . .

XI I Average Changes from Pre-Treatment to Post-

Treatment Measurements of Physical Fitness Sub-Tests in Gresham Wellness Program . . 82 
XIII Pearson Product-Moment Correlation Coefficients Between Health Factors in Gresham Wellness Program . . . . . . . . . . . . . . .

XIV Dunnett $t$-Test of Physical Fitness and WellBeing Means (Adjusted to Pretests) of Gresham Wellness Program . . . . . . . 86

XV Distribution (Percent of Gioup) of Treatment Group in Categories of Physical Fitness. . 94

XVI Distribution (Percent of Group) of Treatment Group in Categories of Mental Well-Being. . 96

XVII Distribution (Percent of Group) of Control Group in Categories of Mental Well-Being. . 96 
CHAPTER I

\section{NTRODUCT ION}

\section{Recent Changes in Health Problems and Solutions}

The present American lifestyle is responsible for more deaths in the United States than any other factor, is responsible for $r$ ising costs of hospitalization that could bankrupt the country (BIue Cross of Oregon, 1981, p. 2), robs industry and schools of valuable employees through premature death, absenteeism, and lowered productivity (Berry, 1981, p. 5), and reduces the quality of 1 ife for a majority of Americans. Despite a growing awareness, increased health-related activities, and promising research findings, most Americans persist in destructive lifestyle practi:es.

Changing Nature of Health Problems

In "The Good Life, It Can Kill You" (Blue Cross of Oregon, 1981), vaceines, improved sanitation, antibiotics and other medical advances are credited with conquering the scourges of the past; however, over the past 50 years, our unhealthy living habits have grown into a gigantic new disease that kills 7 out of 10 people. "The biggest killers today--heart disease, cancer, stroke, and accidents--along with cirrhosis of the liver, bronchitis, emphysema, and asthma, kill $76 \%$ of the 2 million Americans who die each year" ( $p .2)$. "Coronary heart disease, hypertension, 
obesity, diabetes and other conditions related to nutrition account for well over half of all deaths each year" (Parkinson, 1982, p. 173). "American people are presently dying mostly from diseases associated with over-consumption" (Conners, Note 1 ).

Total medical care in the United states is increasing at an alarming rate; in 1960 , it represented $5.3 \%$ of the Gross National Product; in $1980,9.4 \%$. "If permitted to continue, 1985 yearly costs are expected to be about $10 \%$ of the Gross National Product, or $\$ 1,946.50$ per person" (Parkinson, p. 1). Health care is reported by Tager and Goldberg (1982) as having "mushroomed" from \$192 billion in 1978 to $\$ 279$ billion in 1981 . (p. 12) More disturbing is the belief expressed by Blue Cross of Oregon (1981), "We are spending $\$ 104$ billion a year for health care that some experts say we should not need." Further, "National health insurance programs could bankrupt the country if our health care system continues to spend millions treating disease after it strikes, instead of preventing it" (p. 2). Health care is now the third largest industry in the United

States. (Ferguson, 1980, p. 244)

In "Fitness in the Workplace" the President's Council on Physical Fitness (Note 2) described health problems facing business and industry today. (1) Premature deaths are estimated to cost $\$ 25$ billion annually. (2) Recruiting replacement annual costs are $\$ 700$ million. (3) Chronic 
fatigue and lethargy sap efficiency and productivity and increase the probability of accidents. (4) Excessive sick leave is estimated to be three to five days per person per year. (pp. 5-6) Jennings and Tager (1981) estimated health benefit costs to employers "have increased more than $800 \%$ over the past 25 years" (p. 14). Because the health care costs incurred by a company come also from the family and the retiree, corporate concern is extending to dependents as well as active employees. (Parkinson, 1982, p. 1)

Trend Toward Redefining Health

A growing health concern in the United States goes beyond a consideration of premature death and illness and addresses the quality of life.

There are many degrees or levels of wellness, just as there are degrees of illness. Nor is wellness simply the absence of disease. While people often lack physical symptom, they may still be bored, depressed, tense, anxious, or generally unhappy with their lives" (Ryan \& Travis, 1981, p. 2 ).

Ardell and Tager (1981) proposed wellness as a lifestyle stressing the benefits of "a zest for living" and the goal of "your best possibilities for well-being" ( $p .12$ ). John $\mathrm{Na}$ isbitt (1982), who has yearly analyzed 6,000 newspapers in the United States during the last twelve years, has identified a trend toward self-help as one of twelve recent "megatrends." He concluded that the redefinition of 
health has changed from the "mere absence of disease to the existence of a positive state of wellness in the whole person... Wholistic health simply means dealing with the body, mind, and emotions as a whole" (p. 137). Drolet (1982) reported "a change of attitude toward health--a harmonious blending of physical, mental (including emotional), social, and spiritual well being serves as the positive model for 'health'" (p. 1).

The Surgeon General's report, Healthy People (United States Department of Health, Education, and Welfare, 1979 , p. 280) stated the growing belief among health experts that further improvements in the health of the American people will be achieved through a national commitment to efforts of health prevention and promotion.

\section{Trend from Institutional to Self Help}

Ardell and Tager (1981) stressed the importance of the individual in health promotion, "Modern medicine is such a wonderful thing that there are two problems: people expect too much of it and too little of themselves" ( $p$. 17). Further, "Other factors under your control, such as the extent to which you place yourself at risk, are ultimately more influential than the quality and availability of medical care" (p. 16). John H. Knowles, president of Rockefeller Foundation, wrote that the next major advances in the health of the American people will result in the 
assumption of individual responsibility for one's own health. "This may require a change in lifestyle for the majority of Americans" (BIue Cross of Oregon, 1981, p. 2). Naisbitt (1982) reported, "America's loss of faith in the medical establishment gave a strong symbolic push to the paradigm shift from institutional help to self-help" ( $p$. 133). "The trend has been strengthened by the triumph of wellness over the old model of illness, drugs, surgery, and treating symptoms rather than the whole person" ( $p$. 134).

Changing Individual Lifestyles as a Solution

The description of a lifestyle that could lengthen life, improve the quality of living, and reduce costs is available but many of the changes necessary are not under the influence of medical science; factors such as smoking, dieting, exercising, coping with stress, and practicing safety are at the control of the individual. (United states Department of Health, Education, and Welfare, Living Well, p.4) A reduction in these $r$ isk factors could substantially "reduce 7 of the 10 leading causes of death in the United States" (United States Department of Health, Education, and Welfare, Living Well, p. 10).

Lester Breslow concluded that "by switching from a bad lifestyle to a healthier one, a person can figure on adding 14 years to his 1 ife" (BIue Cross of Oregon, 1981, p. 6). He based this statement on a five and one-half year 
study of 7,000 selected adults in northern California. Health habits associated with longer life were: eating three meals a day, moderate exercise, not smoking, maintaining moderate weight, and moderate use of alcohol. Medical Datamation (1976), an organization that measures health hazards, claimed the risk of dying stems from family medical history, existing conditions, and health habits. "Many factors can be altered favorably--diet, exercise, use of smoking/alcohol, stress, and attitudes and support" ( $p$. 2). Seventh Day Adventists have been shown to have a death rate due to cancer, heart diseases, and pulmonary diseases that is $50 \%$ less than the national average. This is relatd to their distinctive diet and 1 ifestyle. (Blue Cross of Oregon, 1981, p. 6)

\section{Health Promotion on the Corporate and National Level}

On the national level, interest in health promotion is reflected in the 1978 Report of Health, Education and Welfare, the 1979 Surgeon General's Report, Healthy People, the 1979 National Conference on Health Promotion Programs and the 1980 Health Objectives for the Nation. All these publications and conferences designate "disease prevention and health promotion as major health initiatives" (Parkinson, 1982, p. 8). Business is interested in health promotion for a number of reasons: (1) reduction of health benefit costs, (2) improving productivity, (3) fear of 
government mandates, (4) and improving the corporate image by providing that in which employees have a growing interest. (Jennings \& Tager, 1981, p. 16.) The present illness care system (community-physician-hospital) is broadening its function to health promotion although "there are embedded constraints in the system that will seriously blunt it's contribution ... for the next five to ten years" (Parkinson, 1982, p. 119).

\section{Problems of Changing Lifestyle}

Despite the research evidence of the value of health promotion, the abundance of lifestyle practices that give promise of lengthening and improving the quality of 1 ife, and the efforts of government and business, a majority of Americans "either ignore preventive health measures or are unwilling to make the specific effort to change long established habits of an unhealthy lifestyle" (Argeropoulos, 1981 , p. 1). "Traditional approaches in attempting to help individuals achieve health and safety through their own efforts have not been effective" (King, 1982 , p. 35). The acquisition of knowledge does not necessarily lead to developing and maintaining desirable practices. King (1982) reported that, when 26 health majors were asked to identify the most important meal of the day, they were $100 \%$ correct in naming breakfast; however, only four regularly ate breakfast. (p. 35) 
In $1979,92.5 \%$ of people questioned in a Harris poll agreed'with this statement: "If we Americans lived healthier lives, ate more nutritious food, smoked less, maintained proper weight and exercised regularly, it would do more to improve our health than anything doctors could do for us" (Parkinson, 1982, p. 7). The data reveal a wide discrepancy between this belief and actual behavior. For instance "nearly half of Americans are overweight...and fewer than one-third follow the widely publicized recommendation to exercise vigorously at least three times a week" (Parkinson, 1982, p. 7). "Research has consistently shown that good advice on food consumption is rarely followed. Programs for weight loss, for example, have been notoriously ineffective" (Parkinson, p. 174). Half the patients who begin treatment for hypertension do not remain under care despite the fact that effective treatment is available and the patients are aware of its value. (Parkinson, 1982, p. 163)

Recent Health Activities Lack Sound Basis

There is encouraging evidence that increasing numbers of people are beginning to actualize a new-found personal responsibility for health. (Naisbitt, 1982, p. 134) There has been $100 \%$ increase since 1965 in the number of people exercising in some way, butter consumption is down $28 \%$, and smoking is down the same percentage in the same period. 
More than 500 companies in the United States have fitness programs with directors. In the 1970's, interest in diets and nutrition soared; running and jogging became a mass movement soon after. (p. 133)

The recent public interest in health has produced a proliferation of popular publications, health elubs, health and fitness counselors, and even changed our notion of physical beauty--lean is in. A growing portion of the population, eager to reap the benefits of better health, is accepting fad diets and misinformation along with the research evidence of the real experts. (Hopper, Note 3 ) There is a danger that improperly conditioned people may exceed their physical capacity in poorly managed sports programs (President's Council, Fitness in the Workplace, Note 2, p. 4) and that "popular diets are often irrational, distorting, or ignoring principles of good nutrition." (Nash \& Ormiston, 1978, p. 4). Beck (1982) claimed that "although numerous authors have espoused the virtues of attempting to motivate patients to assume responsibility for their own health, there appears to be little systematic research directed at how this should be accomplished " $(\mathrm{p} .38)$.

\section{Implications for the Public School system}

There are two implications of the problems of health promotion for the public school system: (1) elementary and 
high' school education should include knowledge, decisionmaking skills, and values that will prevent a repetiton of the destructive life-style practices of the present generat ions and (2) the reduction of absenteeism, "burn-out", premature death, and lowered energy could increase the productivity of the school staff. Present State of Health Education

Passwater (1980), in reviewing the literature concerning nutritional education in public high schools in the United states, reported a history of nutritional misinformation and misconceptions from 1967 to 1980. (pp. 24-27) Even in the instances where apparently adequate programs existed, "there was a low correlation between health knowledge and behavior" (p. 27). Ardell and Tager (1981), in advocating modern health promotion principles, stated that "the values that we have been taught in public schools generally do not support wellness" (p. 21). Conrad (Note 12) quoted President Carter as saying that the national youth fitness scores "have not improved in the last 15 years" ( $p$. $8)$.

Present recommendations for health program adoptions in the state of Oregon by the state consultant for health and physical education, Len Tritsch, contain the wellness theme. Topics that reflect this theme are decision making and communication, skills in monitoring one's own health, and the importance of aerobic exercising. (Note 4 , Note 5 , 
and Note 6) Tritsch has had a significant effect in promoting wellness concepts and practices in Oregon schools through the Seaside Health Education Conferences from 1977 through 1982. Unique features of the conferences are self assessment of personal health behaviors, the practicing of wellness recommendations at the conference and, the formulation of action plans to use in the participants' respective schools. Eight other states are modeling Tritsch's Seaside Conference. (Drolet, 1982, p. 3)

\section{School Staff Needs}

The second implication for public school system is for the staff. Not only do teachers need the necessary knowledge and techniques to teach health promotion programs in an effective way, they also "should realize that children must also be able to observe examples of the kind of behavior they are expected to learn" (Rubin, 1978, p. 144). Important to educational administrators are the same facors that are important to business--absenteeism, premature death of valued employees, low productivity and the cost of health benefits to employees, their dependents, and retirees. "There is no doubt that teacher stress, burnout, and job dissatisfaction are critical issues in education today" (Wangberg, 1982, p. 452). "Stress may aggavate the course of all illnesses .... Virtually all illnesses can be handled by the body more effectively when 
stress factors are identified and reduced" (Jacobs, 1982, p. 1).

\section{Statement of the Problem}

With health knowledge and theory that is adequate to increase the quality and length of life, a majority of Americans are not availing themselves of the benefit. Misinformation, societal pressure, and ineffective programs often support a person in unhealthful practices. Despite a recent surge of interest in physical fitness and nutrition, effective practices that change lifestyle behavior are not widely employed. The public school's responsibility to prepare youngsters with promising wellness practices and attitudes is not being met, partially because school staff members do not have the knowledge, skills, or values necessary to teach and model wellness concepts. Further, their own lowered physical and mental health due to stress and $l$ ifestyle practices reduce their general productivity.

\section{Scope and Methods of This Study}

This study investigated the following related topics.

1. Identification of a lifestyle that is compatible with the recommendations of today's leading health promotion authorities.

2. Identification of an effective educational model for producing changes in individuals, particularly the 
staff members of elementary and secondary schools.

3. Identification of the relationship of physical, mental, and behavioral factors in the model wellness program.

4. Identification of effective support systems for individuals engaged in attempting the recommended 1 ifestyle changes.

The methods used in this study were:

1. A review of the literature that deals with wellness and health promotion.

2. Personal involvement of the writer in interviews with authorities in the field of health promotion and in health conferences, seminars, and classes appropriate to the study.

3. The designing and presentation of a 12-week wellness class intended to produce changes in health related activities in the staff members of an elementary and a high school district. The class was pretested and posttested for physical, mental, and behavioral factors. The means of these tests were compared for significant gains for each of the study groups.

4. A controlled experiment in which two treatment groups representing two methods of support was conducted to measure improvement in knowledge, health factors and short-term behavioral practices. Treatment groups were 
each compared with the control group with a Dunnett t-test (Winer, 1962, p. 90 )

5. Studies of the relationship of physical and mental measurements, physical and behavioral measurements, and mental and behavioral measurements were made by comparing the scores collected in the experiment. Pearson productmoment correlation coefficents were used to determine significant differences.

\section{Importance of the Study}

By designing and testing a model of a wellness program appropriate for a school staff, this study could provide valuable information to school administrators who wish to incorporate health promotion in their school curriculum. That health promotion and wellness concepts are vital to the physical and mental well-being of our nation's citizens is well documented; that present health promotion practices while increasing, lack a sound basis in research is also reported by leading health authorities. Since models are generally not transferable intact, this study investigated relationships of physical, mental, and behavioral factors so that future health promotion planners will be assisted in modifying the model program to meet their own needs.

Successful adoption of wellness practices by members of a school staff could lead to modeling of desirable behaviors for students, increased productivity in achieving 
the curricular goals of the school, and reduced costs in substitute teacher and health insurance payments. 
CHAPTER I I

REVIEW OF THE LITERATURE

This chapter presents a review and summary of the literature that describes the content, the programs, and the methods recommended for changing the lifestyle of Americans from current destructive health practices to one. that gives promise of lengthening and improving the quality of life. This literature is usually identified under the title of "health promotion."

Health Promotion

Health promotion literature arises from programs associated with business, hospitals, government, youth organizations, and public schools. Research scientists also contribute to the literature, often through the auspices of universities or one of the institutions cited.

Health Promotion in Business

The first physical fitness program in an American firm began in 1894 at the National Cash Register Company in Dayton, Ohio, with morning and afternoon exercise breaks for employees. Today, more than 400 companies in the nation have established health/fitness programs. While 
many companies build their own facilities, others arrange for participation in community facilities. (President's Council, Fitness in the Workplace, Note 2, pp. 3-4) The primary reasons companies are spending millions of dollars on wellness programs are (1) to decrease sick time, health insurance utilization and accidents and (2) to increase the productivity, as well as the general well-being, of its employees. (Bauer \& Robinson, 1982, p. 37) A Canadian research project contrasted two comparable white collar employee groups--one with a fitness program, one without. Shephard, who analyzed the data, reported savings to the company of 84 dollars per individual for those in the fitness program. (American Health Consultants, 1981, p. 1) Although cost effective data" is not readily available in a usable form" (Parkinson, p. 17), health promotion is making monetary sense to business administration and big business in America has begun "monitoring its weight as closely as its Dow Jones average. Fat is out and thin is in. An employee... who stays healthy is just as valuable as one who can turn a ... profit in the stock market" (Peters, 1981, p. 5).

Health Promotion in Hospitals

Traditionally, hospitals have focused their efforts on curing the ill or injured. "Although this remains the primary function of a health care facility, many hospital 
administrators are realizing both the importance and the value of offering an additional service--health promotion" (North Florida Regional Hospital, Note 7, p. 1). Ferguson (1980) in her widely read book, The Aquarian Conspiracy, described the "emergent paradigm of medicine" (p 246). She wrote, "Medicine is undergoing an amazing revitalization. Patients and professionals alike are beginning to see beyond symptoms to the content of illness: stress, society, family, diet, season, emotions" (p. 242). The new movement "is hitting the old assumptions of medicine hard. The search for self becomes a search for health, for wholeness" (p. 246), from an emphasis on eliminating symptoms to an emphasis on achieving "maximum wellness" (p. 246).

An example of a hospital emphasizing health promotion is the North Florida Regional Hospital in Gainesville, which has "instituted three hospital-based health promotion programs within the past three years." (North Florida Regional Hospital, Note 7, p. 1) The programs are for well people who seek to improve their health. These "wellness" programs consist of good fitness, good diet through nutritonal understanding, stress management, non-smoking and weight control. The Portland (Oregon) Adventist Medical Center (PAMC) (Note 8 ) offers a full wellness program of health assessment, nutritional and fitness prescriptions, evening and weekend classes for the public, exercise logs, 
and assistance to business and school health enterprises. Health Promotion by Government

The national government designated health promotion as a major health initiative through the Department of Health, Education and Welfare (DHEW) reports, reports of the Surgeon General, and national conferences. (Parkinson, 1981 , p. 8) Healthy People, the Surgeon General's report on health promotion and disease prevention (U.S. DHEW, 1979), cited the change in morbidity and mortality in the United States from infectuous diseases to cancer and heart diseases. The report is a compilation of research papers, one large section of which is devoted to "Preventive Services for the Well Population." "Many papers... make strong cases for greater preventive efforts, using means presently available but not fully exploited" ( $p .5$ ). The Public Health Service launched "an intensive effort to improve the health of the American people and contain soaring care costs by establishing comprehensive national preventive objectives in 15 areas" (President's Council on Physical Fitness \& Sports, Note 2). Nineteen public and private agencies were represented on the physical fitness and exercise committee. (p.2). The official statement of the problem by the Public Health Service was:

The health benefits associated with regular physical fitness and exercise have not been fully defined. Based on what is now known it appears that substantial benefits ... are possible. Yet most Americans do not engage in appropriate 
physical activity" (p. 2).

Health Promotion in Youth Service Organizations

An example of a private service organization that is interested in health promotion is the YMCA. In the administrator's guide for the YMCA camp in Frost Valley, New Jersey, the introduction read, "Wellness springs from a growing national awareness that what we do for our health is substantially more than what pills, doctors and hospitals can do "(YMCA, Frost Valley YMCA, 1974, p. 1). The guide explains that the major causes of illness are attributable to lifestyle rather than chronic diseases. "It has become the norm (accepted and expected behavior) in our society to live in a way that is unhealthful" (p. 1). The camp program was devoted to developing "optimal wellbeing" and "finding a sense of purpose and self-esteem" through attention to nutrition, exercise and stress management. (p. 1)

\section{Health Promotion in Schools}

The State Department of Education in Oregon has a strong advocate of health promotion education in Len Tritsch, consultant for health and physical education. For six years, Tritsch has conducted a summer health conference which has had a wide influence on school programs in Oregon. Drolet (1982) found a significant change toward wellness concepts and practices in schools that had sent 
teams of staff members to the summer conferences (called the "Seaside Conferences").

Control group members, who did not attend the conferences, maintained the traditional disease diagnosis and treatment orientation for health education while Seaside participants adopted the wellness model and ... achieved positive status for health education in the curriculum" ( $p .13$ ).

"An outgrowth of the Seaside Conferences was the allocation of federal funds for Nutrition Education Training Programs (NETP)" which subsequently resulted in a greater emphasis on nutrition education in Oregon. (p. 19) Eight other states have used the "Seaside" approach. (p. $60)$

\section{Integrated Versus Single Factor Programs}

Programs that have concentrated on a single health factor generally have not been successful. However, such programs have produced much valuable research. Most programs now recommend integration to some degree.

\section{Dietary Guidelines and Research}

The U.S. Department of Agriculture and the U.S. Department of Health, Education, and Welfare have jointly prepared and distributed "Dietary Guidelines for Americans" (1980). These guidelines were intended to set the patterns for the nutrition projects of the federal government. These guidelines are prepared every $f$ ive years and are "intended for people who are already healthy" (p. 1). The 
guidelines suggested that a person needs (1) knowledge of food selection and the effects of consuming various food groups and (2) a willingness to change some lifestyle habi is. Further, they suggested that nutrition is an individual matter, "People differ--and their food needs vary depending on age, sex, body size, physical activity, and other conditions such as pregnancy or illness" ( .11$)$. Therefore, the improvement of the health of each person is a unique problem that is best solved by each individual. General guidelines proposed for most Americans are: eat a variety of foods, maintain ideal weight, avoid too much saturated fat and chloresterol, eat foods with adequate starch and fiber, avoid too much sugar, avoid too much sodium (salt), and consume alcohol only in moderation, if at al1. (p. 2) However, the "Dietary Guidelines for Americans" contain this reminder, "Food alone cannot make you healthy. But good eating habits based on moderation and variety can help keep you healthy and even improve your health" (U.S.Department of Agriculture and U.S.DHEW, p. 1).

Comparison of the Health of Different Cultures

Conners (Note 1) has shown that the dietary habits of different cultures are related to the chloresterol level in the blood and to the mortality rates due to heart disease. The Taramara people of Mexico, who exist mostly on corn and beans, have a very low incidence of heart disease compared 
to people in the United States. The death rate from coronary heart disease in Japan is low compared to the United States, a fact that Conners related to the difference in the meat diet of the two populations. The coronary death rate is declining in the United States, Canada, and Australia in the last few years, years in which dietary habits in these countries changed; England, with no change in diet, showed no change in coronary heart disease rate (Note 1). These comparisons, however, are among cultures where physical exercise also vary. The Taramara people have long led a vigorous, primitive life; the United States is just undergoing a mass movement to exercise.

Weight Reduction Programs

Parkinson (1982) reported that weight reduction programs often have only short range benefits. Eleven studies of weight reduction programs that were pretested and posttested involved 501 persons who were mildly overweight. After eight to twelve weeks of treatment, the group receiving treatment showed greater weight lösses than groups not receiving the treatment. (Parkinson, p. 179) However, follow-up studies caused Peikinson to conclude, "Although some people may lose a few pounds while actively following a treatment program, none of these treatment techniques has been shown to result in significant long-term success for most obese people" (Parkinson, p. 174).

Tucker (1982), explaining "setpoint theory", con- 
tended that "it is difficult for overweight people to achieve permanent weight loss by dieting because the body seeks to maintain its level of stored fat within a narrow range" (p. 84). While experiments have shown that the setpoint is highly resistant to dietary manipulations, physical exercise can lower the setpoint, possibly by affecting the hypothalamus. ( $p$. 88) "Given the existence of a setpoint," Tucker concluded, "the grim reality is that any approach to weight control must be a life-long endeavor.... with no way to turn down the body's fat thermostat other than physical exercise" (p.90).

\section{Limitations of Sports Programs}

The physical activity boom that started in the mid$1970^{\prime}$ 's has resulted in substantial changes in the exercise profiles of American adults. "Evidence... supports the belief that an increase in habitual physical activity promotes better health" (Parkinson, p. 253), however, conventional notions of physical activity can be misleading.

Although 50,000 business organizations have some sort of organized recreational programs--sports teams, jogging tracks, ... clubs, etc.--these programs do not necessarily mean the kind of regular, vigorous exercise the experts say is essential to improve and maintain fitness. Employee sports programs that fail to include training and fitness related activities may even be dangerous, since deconditioned people ... may exceed their physical capacity. (President's Council, Fitness in the Workplace, p. 4)

Participants should be aware that cardiovascular 
improvement requires a sustained elevation of the heart rate, that muscles need to be stressed, and that joints must work through their full range of motion. "Fitness programs should be vigorous and sustained" (President's Council, Fitness in the Workplace, Note 2, p. 9).

Integration of Physical and Nutritional Programs

Programs that integrate physical fitness and nutrition are believed to give greater promise of success than single factor programs. Bailey, in Fit or Fat, (1978) claimed that dieting alone will not work. (p. 2) He explained that through aerobic exercising and proper eating "you can change your body to become more proficient in using fat" (p.74). His program advocated exercising at $80 \%$ of an individual's maximum heart rate for periods of 12 to 20 minutes four times each week. (pp. 23-28) His methods required constant self-monitoring of the pulse rate and a decrease in the consumption of sugar, unsaturated fat, salt, and red meat, with a corresponding increase in fiber and fruit. (pp. 83-88)

Malinow (Note 9) explained the benefit of an integrated program. There are two ways, he said, of reducing plague build-up in the coronary arteries: one is by decreasing the amount of low density chloresterol (LDL) in the blood through dietary means; the other is by increasing high density chloresterol (HDL) through exercise. 
Integration of Physical and Mental Health

Ardell and Tager (1981) described their wellness program as "wholistic--embracing physical, emotional and mental health" (p. 14). It is more than nonsickness, emphasizing physical fitness, stress management, nutrition and being sensitive to the body's external and internal environment. Ryan and Travis (1981) suggested that wellness is not only an integration of body, mind, and spirit; it is "a decision", "a process", "an efficient channeling of energy", and "a loving acceptance of yourself" (p. 1).

Jacobs (1982) described the effect of stress on physical and emotional health; "Our bodies respond to stress in a variety of ways. Common ailments such as insomia, fatizue, intestinal dysfunction, headache, backache, anxiety, frustration and depression are often due to stress"( $p .1)$. Further, "stress may aggravate the course of all other diseases as well" (p. 1). Wangberg (1982) recommended physical exercise and nutritional diets (among other things) to reduce stress. ( $p .453$ )

It is now well established that exercise releases antistress chemicals within the brain and spending 20 minutes three or four times a week engaged in simple, pleasurable physical exercise increases mental flexibility and stress-coping capacity" (Jacobs, 1982, p. 2 ).

Ferguson (1980) described a shift from "body and mind are separate" to a "bodymind perspective" as an essential part of the "emergent paradigm in medicine" (p. 246). 
"What constitutes a basic wellness program is simple and uncontroversial," she wrote, "regular exercise, no smoking, a healthy diet (low-to-moderate intake of fat, salt, sugar and alcohol), adequate rest, and stress control" (p. 137).

Agreement of Major Wellness Proposals

The integration of exercise, nutrition, and stress management is reflected in programs proposed by writers, researchers, and other health-related organizations. The Frost Valley YMCA 1 isted six interrelated goals of their camp program: enjoying fitness, eating well, taking care (hygiene and safety), enjoying life, relating to others, and being a part of the world. (YMCA Frost Valley, New Jersey, 1974, p. 3) In summarizing health promotion in the workplace, Parkinson (1982) devoted chapters to hypertension control, weight control and nutrition, control of alcohol and drug abuse, smoking cessation, stress management, physical activity, and self-protective measures against hazards. (p. vii) The health promotion goals of the United States Public Health Service for 1990 are grouped in these categories: Smoking and Health, Misuse of Alcohol and Drugs, Nutrition, Physical Fitness and Exercise, and Control of Stress and Violent Behavior. (U.S.DHEW, Promoting Health, 1980) The Wellness Center of North Florida Regional Hospital (Note 3 ) claimed that "wellness consists of good fitness, good diet through 
nutritional understanding, stress management, non-smoking and weight control" (p. 1). Ardell (1979) and Ardell and Tager (1981) proposed a five dimensioned program: (1) physical fitness, (2) nutritional awareness, (3) stress awareness and man- agement, (4) environmental sensitivity (which includes safety, smoking and drugs), and (5) self responsibility. (p. 14)

\section{Institutional Help Versus Self Help}

Ardell and Tager (1981), while offering a structured program, nevertheless, stress the individuality of wellness programs.

There is no way we or anyone else can tell you how to live a wellness lifestyle. There are no... authority figures who could describe exactly what you ought to do .... to insure the highest returns. We can provide advice, information and alternatives .... You will be encouraged to find your own applications" (p. 15).

National Trend toward More Self Help

Naisbitt (1982) wrote that there were three major reasons for the shift from institutional help to self-help: (1) a new found sense of responsibility, (2) discovery of areas genuinely not needing professional care, and (3) the triumph of preventive and wholistic care over traditional treatress of illness model. He also cited the reason of a loss of faith in the invulnerability of the medical profession. (p. 133) Naisbitt wrote, "In our minds tech- 
nology is always on the verge of liberating us from personal discipline and responsibility. Only it never does and never will" (p. 53 ).

\section{Institutional Help Still Needed}

While there is agreement that there should be greater self-help and individual responsibility, there is also evidence that institutional help is needed by a majority of people to some degree. Benson (North Florida Regional Hospital, Note 7 ) observed that:

Given ten potential participants in a behavior modification/lifestyle change program, the odds are that two will never start, two others will agree that they ought to change, start, and quit at the first excuse. Four people will start, complete and succeed if the program is a good one. The last two will succeed with or without a program (p. 7).

With this consideration, six of ten individuals could be helped by a good institutional program.

Common features of successful promotion programs in the workplace, according to the President's Council for Physical Fitness (Note 2) include much intitutional involvement: (1) a high level of support by the administration and the labor organizations; (2) strong leadership by those who have solid training in principles of exercise and motivation; (3) accessibility of facilities; (4) availability of time when staff can participate; (5) confidential screening and assessment; (6) recording of progress; and (7) group participation--most people do not like to 
exercise alone. (p. 7) While the ultimate responsibility for behavioral change rests with the individual, "merely offering space and time for a fitness program is not enough," the Council continued, "The company must provide a program of incentive and motivation." (p. 3 )

The solution becomes one of providing a program with the institutional help that rewards and reinforces individual responsibility.

\section{Developmental Levels of Behavioral Change Programs}

Successful wellness programs have developed through the following levels of needs and objectives.

1. Awareness--individuals need to become aware of their health habits and of the consequences of these habits.

2. Knowledge--individuals need pre and post knowledge, alternatives available, and results of research.

3. Attitudes and Beliefs--individuals need to establish a favorable attitude and a belief that favorable results are possible.

4. Behavior--individuals change their behavior with regard to health practices. Although some behavioral changes may occur in a short time, maintenance is more difficult.

5. Risk Reduction--Three to five years are often necessary to assess significant changes in the risk to the 
individual.

6. Reduction in Morbidity and Premature Mortality--a

hoped for goal that is hypothesized if number four and number five are maintained. (Parkinson, p. 18)

Metress (1982) reminded the health promoter that "even though a vast amount of information is published routinely, it does not all make its way to the public. She advocated greater dissemination of accurate information. (p. 23 )

King (1982) wrote, "traditional approaches such as 'telling and testing' and values clarification, have not been effective in helping pupils maintain or develop desirable health practices." "Therefore", she concluded, "the health educator should focus on actions and practices" (p. 35). Conrad (Note 12) wrote, "In considering how to address the problem of the non-exercisers in this country, I keep returning to the fact that knowledge is well ahead of practice" (p. 10$)$.

More and more educational programs are focusing on the short-term behavioral change as the end product. Recent research suggests that although changes in knowledge and attitudes are important, they often bear scant relation to actual changes in behavior. Risk reduction and premature mortality are hypothesized but their realization cannot be realized in most assessment or research projects. 
Focus on Short-Term Behavioral Change

Understanding does not guarantee effective action ... and this is the point at which ... behavioral psychology is needed. To successfully resist pressures and overcome suceptiblities, a person needs training in social and psychological skills. Examples are assertiveness training, role playing and social reinforcement" (U.S. DHEW, Healthy People, p. 203).

Parkinson (1982) noted that in the area of weight control:

In the past ten years ... a new strategy has been aimed at teaching people not only what to eat but how to adhere to a recommended diet. A number of techniques directed at behavior change have shown some recent success in altering habits that traditionally have been extremely difficult to reform" (p. 174).

\section{Self Management}

The best behavioral approach for weight control according to Nash and Ormiston (1978), is one that helps develop self-management skilis by providing training in problem solving, behavioral training, thought management, nutritional information, and exercise. (p. 8) Their behavioral modification approach develops through the following sequence.

1. Self Observation, data, and record keeping.

2. Analyzing problems

3. Setting reasonable goals

4. Adopting tactics

5. Evaluating progress 


\section{Trying alternatives.}

7. Updating solutions as need changes

"The key to progress is to set short term, reasonable goals"--challenging but with room "to be human" (p. 15). The biggest problem is the extensive record keeping, but "when record keeping is omitted, a very important part of the behavioral approach is missing" (p. 8).

Farquhar (1979) suggested essentially the same program for "self-directed change" in stopping smoking: (1) accept the problem, (2) build confidence and commitment to quit, (3) develop awareness of why, where, and when you smoke, (4) develop and implement an action plan, (5) periodically evaluate the plan, and (6) maintain a degree of nonsmoking. (

\section{Problem Solving Approach}

Ardell and Tager (1981) advocated a problem-solving approach to behavior change in their wellness program. Recommended steps were that individuals establish personal baseline data, brainstorm goals and solutions, list barriers and obstacles, and make commitments toward short-term goals. Record keeping of accomplishments and the periodic updating of goals were considered important. "You have to make some decisions eventually, and these decisions should grow out of personal assessments and an appreciation of your own expectations and desires" (p. 15). The authors ask 
for "a commitment to the positive" (p. 14).

Motivation and Reinforcement

Langlie (1977) specified two hypotheses regarding an individuals readiness to engage in health promotion programs: (1) perceived vulnerability and perceived seriousness of the consequences of disease and (2) the belief about the relative effectiveness and availability of alternative actions. (p. 245) Beck (1982) believed "health threat warnings are likely to be effective only when people believe in their ability to control the particular threat in an effective manner." He called this belief "personal efficacy" (p. 39). For this reason, he thought it necessary to show cause-effect relationships to a patient as clearly as possible. Further, he advocated "direct feedback of one's success" and "gaining expectations of success" (p. 39,40). Tager and Goldberg (1982) did not believe that scare tactics (consequences of health risks) were good motivators, "there must be an emphasis on positive payoffs" (p. 13). King (1982) described positive reinforcement as the most powerful motivator in developing, maintaining, and/or changing specific behaviors. Bauer and Robinson (1982) pointed out the importance of continuous promotion in the early stages of fitness programs, since "positive results are generally not objectively measurable in the early stages" (p. 39). "While the em- 
ployee awaits the gradual rewards for lifestyle changes, he/she will be bombarded with conflicting messages from junk food manufacturers, friends, health agencies, and schools." (p. 43).

\section{Personal Goal Setting and Self Monitoring}

A factor associated with success in 11 studies of treating hypertension (Parkinson, 1982, pp. 167-169) was setting goals and contracts that provided tangible reinforcement. Other positive factors were increased contact between provider and patient and "some of the studies found an added effect when patients were given the opportunity to monitor their blood pressure and keep records of change" (p. 169). Stevens (1978) recorded a student's successful attempt to achieve the goals of a self-management endeavor by self-monitoring, record keeping, stimulus control and disclosure of results to others. (p. 17)

\section{Stimulus Control}

Stevens and Spurr (1978; Note 10) further discussed stimulus control as identifying stimuli that trigger undesirable responses and then avoiding them, changing them, or arranging alternative responses if they cannot be avoided or changed. Stimulus control (for increasing study time) was enhanced by working at the same time every day in a place where distractions had been removed. (Stevens, 1978 , p. 203) Alternative responses to stimuli for eating, 
Stevens suggested, were deep breathing, a hot bath, walking, calling a friend, or having fresh fruit on hand. (Note 10) Stevens also reported that students in a class he conducted experienced success in self-control, "but only when meeting as a group"; he wrote "clearly, the regular disclosure of behavioral records may be quite powerful" (Stevens, 1978, p. 204).

\section{Value of Support Systems in Changing Behavior}

Although psychologists know that praising and rewarding appropriate behavior is the best means of bringing about behavioral changes, most people are not skilled in its use; "people need to learn support skills" (Nash and Ormiston, 1978, p. 277).

Support from Others: A Basic Need

"Basically, all humans and all primates have needs which can be satisfied only through social interation with others" (Kaplan, Cassel, Gore, \& Susan, 1977, p. 50). "There is evidence," they added, "that loss of social support leads to unmet needs" ( $p .50)$. This evidence is contained in the following types of studies: (1) high death rate for spouses followed the death of a partner, (2) relocation in a new neighborhood caused needs that were met only with difficulty, and (3) often observed inappropriate behavior of newly institutionalized populations. ( .50 ) 
Naisbitt (1982), in Megatrends, used the term, "high tech/high touch." He wrote, "the more technology that we introduce into society, the more people will aggregate, will want to be with other people" (p. 45). Predictions that home TV would cause movie theatres to be non-existent by 1980 were made by people who did not understand "high tech/high touch." People do not go to a movie just to see a movie. They go to cry or laugh with 200 other people. (p. 45) "In our factories we are also moving in dual directions: high-tech robots and high-touch quality control circles--groups of workers who discuss work-related problems and solutions." (p. 49) William Onchi's Theory Z management styles stressed long term employment, consensual decision making, slow promotion and evaluation and wholistic concerns. "Type Z organization provides a sense of belonging needed now in American society" (Naisbitt, 1982, p. 203 ).

Support by a Significant Other Person

A common observation of eleven industrial programs to control hypertension was the involvement of "a significant other person", in addition to the patient and the health care provider. (Parkinson, 1982, p. 169) Two University of Michigan studies tested the hypothesis that the enlistment of a partner would increase blood pressure control; preliminary analyses suggested positive results. (Parkinson, 
p. 169) A North Carolina study at Chapel Hill successfully mobilized the effect of social support through family members or friends. (Parkinson, p. 169) Respondent perception of what motivated individuals to continue wellness programs were reported by Bauer and Robinson (1982) to include competition and "support of significant others," e.g., spouses, colleagues, as of primary importance. This finding, they believed, provided support for the inclusion of spouses in the program. ( $\mathrm{g} .43$ ) The President's Council (Note 2) also reported that "many companies find that fitness programs are particularly successful when they include the spouses of empioyees. (p. 11) Ardell (1979) in describing "high level wellness" wrote,

I have tried to emphasize the importance of being connected with others, open to expressing your needs, able to respond with affection and caring to friends, and deeply aware of the value of being interdependent and part of a human network. All this is possible with and complementary to an active sense of self-responsibility for your own life (p. 110).

Taylor (Note 13) made suggestions for preventing tensions from building up to a damaging degree: (1) talk things out with a good friend, expressing emotions knowing that others care and understand, and (2) develop a circle of friends and acquaintances. Many and varied social relationships generally provide stimulation that tends to reduce tension. (p. 8) Feitler (1982) collected data from 3,300 public school teachers regarding stress. The most 
popular coping strategy named in the survey by teachers was talking to a friend. (p. 457)

\section{Informal Social Support}

Informal social support systems include "naturally occurring helping networks" that can be a "key resource in daily coping and emergency assistance for the average person" (Hamburg \& Killelea in U.S. DHEW, Healthy People, 1979, p. 263). "Reviewing both animal and human studies Cassel1 (1974) found evidence to suggest the ameliorative effect for the individual of the presence of significant others during periods of stress" (in U.S. DHEW, Healthy People, p. 256). Cobb defined social support as "information that tells a person that he/she is loved, valued and is part of a network of communication and mutual obligation" (in U.S. DHEW, Healthy People, p. 256). Caplan wrote that "support systems are ... attachments between individuals, ...that (1) promote emotional mastery, (2) offer guidance .... and (3) provide feedback ... which validates identity and fosters improved competence" (in U.S. DHEW, Healthy People, p. 256). Examples of social support systems are families, friends, neighbors and community institutions. (U.S. DHEW, Healthy People, p. 46) In a nine year follow-up of 4,725 residents of Alameda County, California, the connection between the individual's social support systems and their mortality rates were studied. With few 
exceptions, respondents with marriage, family or friends, religious, or other group membership had lower mortality

rates than respondents lacking such connections. (Medical

Self-Care, $1979 / 80$, p. 2) Further, the report continued,

More recent studies have shown that maintaining a close-knit network of family friends is as important a self-care practice as wise eating, staying in shape, avoiding smoking and excessive orinking, or dealing with stress" ( $P .1)$.

\section{Organized Support Groups}

Wangberg (1982), studying stress in school teachers, wrote,

Teachers tend to work in isolation, yet they undergo similar stresses .... Teachers tend to internalize their difficulties....We need to develop environments where teachers can admit failures, share successes, and support one another .... Support groups provide such environments. Support groups could meet at regularly scheduled times .... or between times individual members can give support through phone calls, notes, or visits (p. 453$)$.

"It is not surprising that ... hospitals throughout the nation are opening their doors to a wide variety of medical self-help groups" (President's Council, Promoting Health, Note 2, p. 6). The American Hospital Association (1982) stressed the dual benefits of self-help groups as improving their patient's health and the reduction of expensive hospital care. (p. 1) Naisbitt (1982) described the trend toward networking in the United States: "Networks exist to foster self-help, to exchange information, to im- 
prove productivity ..., and to share resources" (p. 192). "Thousands of organized networks become stable, ongoing organizations, but others remain fluid and open, dissolve, their members resurfacing elsewhere to create new networks" (p. 193).

Hamburg and Killelea (in U.S. DHEW, Healthy People) suggested that "mutual help groups" may be particularly helpful in managing life-cycle transistions, in dealing with long-term deficits ..., and in changing noxious habits and lifestyles" (p. 267). They defined mutual help groups as "associations of people who share the same life situation for the purpose of mutual aid." (p. 266) In mutual help groups, each person assumes a variety of roles, such as helper, helpee, fellow-sufferer, reinforcer, or a veteran of the experience. (p. 266)

Organization of Self-Help Groups

Reissman (1979/80) stressed the importance of autonomy in managing mutual-aid groups; "although they are supported and brought together by outside agencies, they must be run by the clients....Professionals may help such groups, may serve as consultants and advisors, but it must be the group members who are in charge" (p. 19).

The basic principle of "quality circles" is that the expert in any particular job is most often the person performing the job. Quality circles ( $Q C^{\prime} S$ )--a hybrid of 
Japanese and traditional American management practices--are small groups of perhaps ten workers doing similar work who meet to discuss and solve work-related problems. In companies where $Q C^{\prime} s$ have been used production is increased and absenteeism reduced. (Naisbitt, 1982, p. 201)

Shared Decision Making

Project Leadership (Note 11), an organization that provides training for educational administrators, cited "perceived and documented strengths of shared decision making" as follows.

1. Teachers, like other employee groups, tend to take greater responsibility for those decisions in which they have participated.

2. Involvement is a powerful factor for the development of commitment.

3. Many groups report that the quality and substance of decisions have improved.

Guidelines for support groups (Wangberg, 1982) usually provide for members to be (1) from similar circumstances, (2) non-competitive, (3) willing to give constructive criticism, and (4) committed to staying in the group over a period of time. (p. 453) The Challenge Process (attributed by Wangberg to Sparks) applied the techniques of group problem solving in support groups and 
focuses on the positive--working on challenges rather than on problems. The groups work through three stages: stating a challenge, brainstorming suggestions, and making a contract. (Wangberg, 1982, p. 455)

Role of a Consultant in Support Groups

Nash \& Ormiston (1978) wrote that behavioral change can best occur in small groups that meet regularly with a consultant. By sharing problems and brainstorming to generate possible solutions, each person in the group learns from the others. The functions of the group process are (1) sharing and evaluating goals, (2) generating potential solutions to problems, (3) helping with setbacks, (4) giving perspectives on individual rates of progress, and (5) participating in each other's successes. (p: 27). Nash \& Ormiston (1978) approved of the social support offered by Weight Watchers but believed that the groups (30--50) were too large for important group functions to occur. (p. 7 ).

Gaasholt (1980) described the use of "self-formulated study groups" that used consultants. She cited the intentions of such groups to have been to bring theory closer to practice by ecnouraging students to solve personal problems that related to the field of $s t u d y$. She believed it "essential ... in the beginning stages ...to discuss relevant problems which in turn can be restated as goals" ( $p$. 4). Students who applied for her program were assigned to 
groups of 5-28 members (which was then assigned a consultant), and were given instruction in group processes. (p. 5) Instructions included roles, trust, group climate, hidden agendas, and decision-making processes. (p. 6) The dropout rate was high--35\% of the groups lost 50\% of their participants; there was a high level of frustration in the initial period; and there was a great disparity in the success of various consultants.

Miles and Stubblefield (1982) described three types of learning groups: leader-centered, content-centered and group-member-centered. In the leader-centered group, the teacher may set the agenda (or assist the class) and interaction is primarily between individuals and the leader. In the content-centered group, the leader performs both a content and a process function. In the group-member centered learning group, a "trainer" is available for problems in communication, self-understanding, decision making, and group functioning. Roles are temporary; leadership is a function of the total group. All members must take the responsibility for their own learning. (pp. 313-317) To different degrees, all three types of learning groups of fer opportunities for the learners to (1) be actively involved in the process and (2) make use of their own experiences.

\section{Summary of the Literature Review}

Business, government, hospital, private health 
organization and education leaders agree that a change in I ifestyle is necessary to accomplish the next great advance in the health of the American people. The areas most of ten mentioned in the literature of change are physical fitness, nutrition, stress management, smoking/alcohol/drugs control, and safety. Programs that integrate physical fitness, nutrition, and stress management are favored over programs that focus on one area alone. Earlier physical fitness "booms", weight control organizations and clinies for cessation of smoking or drinking are incorporating some or all of the other areas into their efforts.

More programs designed to effect change in lifestyle are focusing on short-term behavioral change. Although knowledge and attitudes are important stages in an educational program, they do not insure changes in practice (behavior). Long-term benefits of risk reduction and decrease in morbidity and premature death are hypothesized when demonstated short-term behavioral changes occur. Techniques recommended to effect short-term behavioral changes are: goal setting, positive reinforcement, self monitoring, record keeping, stimulus control, and modeling of desirable practices. Self-management and problem-solving skills give the greatest hope of changes that will be maintained over a period of time long enough to reduce illness and premature death.

Although effective programs stress the need for in- 
dividual responsibility, the term, "significant others", appears often in the literature as a necessary support for a continued effort. "Others" can be informal acquaintances, spouses, friends, or neighborhood networks; or they may be more organized groups, such as self-formulated study groups, mutual-aid groups, learning groups, and self-help groups.

The advantages of small groups that manage themselves in trying to reach individual goals are believed to be a greater commitment and greater involvement of the individuals, and a pooling of experiences that improves the quality of decisions. The use of consultants with support groups is recommended more of ten than using dominant leaders. A leadership role that is consistent with wellness support groups recommendations is the "content centered leader" (Miles \& Stubblefield, 1982, p. 315) who serves both content and process functions. 
CHAPTER I I I

METHODS AND PROCEDURES

\section{Description of the Wellness Program}

This chapter describes the wellness program, the measurement of the dependent variables, and the methods of statistical treatment that were used in this study.

\section{Hypotheses}

The study was designed to test three research hypotheses gained from the literature review: (1) A twelve-week wellness program based on self-management and problemsolving strategies can produce significant changes in the short-term behavior and health of school staff members. (2) In wellness programs there is (a) a signficant positive correlation between the improvement of physical health and the improvement of mental health and (b) a significant positive correlation between the level of health-related behavior and the improvement of physical and mental wellbeing. (3) Wellness programs that provide leaders for support groups are more effective in changing behavior, improving health, and imparting knowledge than those that provide support groups without leaders. 
Selection and Organization of the Sample

The research was conducted with the staffs of the 11 schools of the Gresham High School District and the Gresham Elementary School District who were invited to participate in a wellness course during the fall term of 1982. Gresham is a suburb of Portlard, Oregon, with two high schools, two middle schools, and seven grade schools. One hundred and forty-nine staff members elected to take the course, approximately one-fourth of the teachers. The enrollees were divided into two treatment groups. Both groups were given the same information regarding factors that could improve their physical, mental and emotional health. Both groups were asked to strive for the same general objectives: (1) acquisition of knowledge, (2) better physical and mental health, and ( 3 ) improved health practices (behavior). One group was organized into support groups of four to eight members; the other treatment group was assigned a leader per school. The objectives were measured respectively by: (1) a knowledge posttest in nutrition, fitness and stress management principles and research findings, (2) pre-and post-physical fitness tests in cardiovascular, strength and flexibility factors, and (3) pre-and post-self-reported inventories of behavior related to health (augmented by weekly reports). All members attended lectures given by authorities in the major areas of health promotion, used the same texts and 
materials, were given instruction in self management, and were asked to maintain a minimum level fitness and nutritional program for eight weeks. A control group of teachers taken from the same schools was given all tests, but not the formal treatment.

Description of the Model Wellness Course

In addition to the eight-week treatment program, awareness activities, pretreatment measurements, and posttreatment testing and analyses were a part of the course. Participants could enroll for college or district credit.

Awareness Activities

All staff members of the Gresham Grade School District were required to attend a one-half day inservice in late september, 1982, to become acquainted with wellness concepts and the district's wellness course. Gresham High School District repeated the program for its staff a week later. Both meetings had been preceded by newsletters to all staff and advanced registration for a wellness course. The inservice programs included an address by the state consultant for health and physical education, Len Tritsch, a "wellness lunch", and a variety of health-related activities. Planning and execution of the programs were done by a team of twenty staff members who had at tended the Seaside Conference in June, 1982 , and were carrying out an 
action plan made at that conference.

Preparation for the Exercise/Nutrition Program

Enrollees in the wellness course took pretests in physical fitness and mental well-being and completed nutritional and behavioral inventories following the awareness meetings. Those data were processed by Portland Adventist Center Health Services personnel and the individual and group results were reported by Dr. Don Hall at the first meeting of the class on October 4. Participants were asked to set goals and complete a contract based on their individual state-of-health reports. Two goals were a minimum requirement of the contract: (1) Physical exercise at the individual's target heart rate for 20 minutes, three times each week, and (2) following the seven dietary guidelines in "Dietary Guidelines for Americans" (U.S. Department of Agriculture and U.S. DHEW). Dr. Victor Stevens of Kaiser Permanete Hospital described selfmanagement practices in the second class meeting and participants were asked to begin their individual eight week programs the next day. Charting of progress, disclosure of progress to a support group, and stimulus control were advised by stevens. During the eight-week period that ended in mid-December, participants were required to submit weekly reports of their health-related behavior on a form provided by the director. Health behaviors on 
the form were rated to a maximum of 100 points each week. (Twenty items, zero to five points each.) The course provided a speaker in each of the five areas identified by the text, Planning for Wellness, Ardell and Tager (1982):

(1) Physical Fitness, (2) Nutrition, (3) Stress Management, (4) Harmful Habits, and (5) Self Responsibility. The course ended with a final knowledge test, a posttest in physical fitness, and the general well-being self-reporting schedule. Each student summarized his/her health-related behavior for the eight weeks of the course and determined a general level of participation based on the weekly reports. Thus, data available for analysis were: (1) pre-and post-well-being scores, (2) behavioral level scores before and during the course, (3) pre-and post-physical fitness test scores, and (4) a final knowledge test score.

\section{Treatment Groups}

Treatment groups for the third hypothesis represented different levels of support. Group $L$ was provided with a health education leaders who assisted each participant in establishing weekly goals, reinforcing successful progress, and readjusting schedules. The leaders were to serve both content and process functions. Students submitted a record of progress weekly to the leader who signed and transmitted the reports to the project director. The group size varied from eight to twenty participants. 


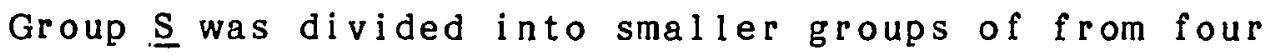
to eight participants and was given brief instructions in group processes; however, there was no designated authority in health education in the group. Participants were to set individual weekly goals in the group setting, brainstorm activities to accomplish the goals, reinforce each other, and share the successes or setbacks in weekly meetings. Students submitted a record of weekly progress signed by two team members directly to the project director through the intraschool mail.

Individuals were assigned to treatment groups on the basis of the school in which they worked or with which they were associated. Thus, one school had only one treatment method which helped to prevent contamination of the treatments. Having determined that a particular school was a

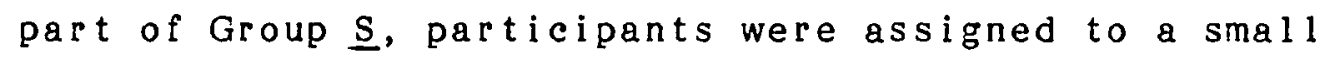
group with the help of the principal and the project director.

A third group, Group $\underline{C}$, was composed of $s$ taff members who participated to a limited degree in the program and were, in some respects, a control group for the formal program. Members of this group took all pre- and post-tests, were free to attend lectures, and were subject to informal staff discussions at lunches and breaktimes. They did not, however, enter into the contract, make weekly reports, or belong to support group designations 
requirements of Groups $\underline{L}$ and $\underline{S}$. They represented a low-level treatment group that "controlled" the formal self-management program.

\section{Measurement of Dependent Variables}

The criteria for selecting measuring instruments for the research were the following:

1. The instrument should purport to measure factors that are directly associated with the objectives of the course.

2. The instrument should have evidence of validity- of measuring what it purports to measure.

3. The instrument's scales should be sensitive enough to show individual and group changes for the periods of time used in the project.

4. The results should be capable of quantitative analysis.

Measuring Knowledge

Knowledge was measured with a criteria-referenced test, composed by the project director, based on the content of the two texts and the presentations of the expert speakers. As such it met criteria 1,3 , and 4 but not criterion 2. The test items were, therefore, submitted to the state consultant of health education, Dr. Len Tritsch, and compared with a similar test given in 1978 by the North 
Clackamas School District. (Note 5) However, the knowledge test was not used as a dependent variable for the experiment. Rather, it was regarded as part of the treatment and as an indication of the degree of participation.

Measuring Physical Fitness

The dependent variables of the experiment were health factors (physical fitness and mental well-being) and health-related behavior. Health factors were measured with tests supplied by the Portland Adventist Medical Center, a physical fitness test (which incorporated the Canadian Test of Physical Fitness) and a mental well-being test (General Well-Being Schedule). (Note 13) The physical fitness test measures four components: (1) body weight and composition, (2) flexibility, (3) muscular strength and endurance, and (4) cardio-respiratory fitness. Activities from the Canadian Test of Physical Fitness were devised and tested on a significant sample of the Canadian work population. Norms for each of the separate tests are based on 6,213 males and 3,651 females; sedentary of light work occupations composed $83.1 \%$ of the female sample and $75.9 \%$ of the male sample. (Canadian Assessment Report, 1979) Therefore, the norms and percentiles were considered appropriate for evaluating the performance of a school staff.

The test devised by the Portland Adventist Medical 
Center (PAMC) was administered under their direction.

Individual subtests (grouped into components) and general method of testing are the following:

1. Body weight and composition--spring scales and skin-fold test with calipers.

2: Flexibility--trunk flexion, reach in inches.

3. Muscular strength and endurance--grip strength (pounds) and number of sit-ups in 60 seconds.

4. Cardio-pulmonary fitness--resting pulse rate, systolic and diastolic blood pressure, and the "step test". Jetti, Campbell, Mangeon \& Routhier (1976) compared the "step test" (that can be performed with simple equipment) with the more direct treadmill test and determined that the maximum oxygen consumption "could be adequately predicted" by using an equation that relates the two performances. (p. 682).

A total score was used by the Portland Adventist Medical Center (PAMC) staff (Note 13) by assigning weights to each performance based on their judgment of the importance of the factor. Thus, the performance of individuals or groups could be compared through individual tests, component scores, or total scores.

Measuring Mental Well-Being

The General Weil-Being Scedule (GWBS) "was developed 
to ascertain how well people are coping with life, particularly in terms of mental and emotional health." The GWBS was developed by the National Center for Health Statistics (U.S. DHEW, 1977) and, after pretesting on 373 adults, was administered to over 6,900 adults as part of a national study which began in 1971 and was completed in 1975. It is a self-reporting instrument designed to assess subjective well-being and distress (p. i i i). Six subscales measure health-worry, energy level, satisfying-interesting 1 ife, depressed-cheerful mood, emotional-behavioral control, and relaxed versus tense-anxious. It also provides a total score.

Interviews by clinical psychologists of 195 students were used to validate the GWBS and several other schedules. "The ... GWB total scale had the highest correlations with the criterion (interviewers' ratings) of the scales compared." (Overall the scales were established as "at the .01 level, or better, of correlation.") (p. 11) The high level of consistency of the GWBS total scale indicated that "it is a homogeneous scale basically measuring a single dimension or general psychological state in this sample." (p. 11) The weakest meaningful property of the GWBS "seems to be in differentiating the total scale into the six subscales." The evaluators believed there needed to be more elements in each. Therefore, "the GWBS seems to present coherent and useful data about the subjective 
well-being of large cross sections of our citizenry" (p. 12). "It should be useful ... as a quality of life index ... and for measuring population changes in sense of well-being over time" ( $p .13$ ). Means, standard deviations, and score ranges were available for the individual items and for the total score. Since the GWBS seem to meet all criteria, it was given pre and post to treatment and control groups, and the total scores of each individual were compared.

Measuring Health-Related Behavior

A search for a validated schedule that would measure the health-related behavior of the participants produced a number of such seales (none with validation studies), but all were incomplete for the purpose. Therefore, portions of schedules that had been used in Tacoma and Kansas were used to compose the schedule that was used in the study. (Tacoma Public Schools, 1980; Kansas Department of Health and Environment, 1978) Scales were designed to agree with the goals of the program. To add to the validity of the instrument, it was submitted to Len Tritsch, state health consultant, to Dr. Don Hall, Portland Adventist Medical Center, and to Victor stevens, Kaiser Permanente, Portland, Oregon. Their criticisms were incorporated into the final draft. To add to the accuracy of the self-reporting, the instrument was part of a weekly report from each partici- 
pant that was signed by support group members in Group $\underline{S}$ and by group leaders in Group $\underline{L}$. Two behavior scores were compared in the study. One, a total of points estimated on the twenty scales before participation in the course and, the other, the general level of behavior maintained during the course, based on weekly reports.

\section{Statistical Treatment of Data}

Hypothesis \#1. The effect of the program on physical health was determined by comparing pre-treatment and post-treatment scores on the PAMC fitness test, using a $t$-test for dependent groups with alpha set at the .05 level. The same test was performed on the pre-treatment and post-treatment total scores of the General Well-Being Schedule. These analyses were done for all three groups separately: Group $\underline{L}$, Group $\underline{S}$, and Group $\underline{C}$. Conclusions were based on significant changes in the two variables (physical fitness, and mental well-being) considered separately in each of the treatment groups.)

Hypothesis \#2. The relationship of mental well-being and physical fitness scores was determined by computing a Pearson product-moment correlation coefficient for the differences in the pretest and posttest scores. Alpha was set at the .05 level. Similar comparisons were made between the physical fitness and the health-reiated behavior determinations. Comparisons were also made between mental 
well-being and health-related behavior.

Hypothesis \#3. The effect of providing different levels of support (Group $\underline{L}$ : leader-led support groups; Group S: leaderless support groups, Group C: no formal support) was determined by comparing the means of posttreatment scores using a Dunnet $t$-test. The means of the treatment groups were adjusted with pre-treatment means (using analysis of covariance) and compared separately with the adjusted mean of the control group. The adjusted means of the treatment groups were compared with each other with a $t$-test. Alpha for each of these tests was set at .05 . Qualitative methods of data collection and analysis were used--in addition to quantitative analyses--to determine the initial balance of subjects, treatment effects, and, in particular, the validity of the self-reported changes in lifestyle behavior. Weekly reports were analyzed for common patterns of motivation. These data were used to support the quantitative analyses and to generate new hypotheses or identify unexpected side effects. 
CHAPTER IV

RESULTS AND ANALYSIS

This chapter will give greater detail concerning specific treatment and data collection, will display the data, and will give specific conclusions and analyses. General conclusions will be made in Chapter V.

\section{Pre-treatment Characteristics of the Sample Groups}

The treatment and control groups were selected from a school staff. A comparison of the demographic and healthrelated characteristics of the school staff and the sample groups was made to help determine the effect of the treatments.

Comparison of $\mathrm{Staff}$ and Sample Wellness Group

The group that participated in the 12 -week wellness program in Gresham schools during the fall term of 1982 was composed of members of the staff (or their spouses) who volunteered after attending a compulsory inservice explanation. As such, they did not constitute a randomly selected sample. Several selective factors biased the selection process: (1) interest, (2) time limitations, and (3) perceived need. Table I compares the demographic characteristics of the sample and the total school staff. The staff composition is given in numbers and percentages supplied by the personnel office of Gresham schools at the 
TABLE I

COMPARISON OF DEMOGRAPHIC CHARACTERISTICS OF GRESHAM SCHOOL'S STAFF AND WELLNESS CLASS PARTICIPANTS

\begin{tabular}{|c|c|c|}
\hline Group & Staff $(\%)$ & Wellness Class (\%) \\
\hline \multicolumn{3}{|c|}{ Sex } \\
\hline Male & $170(40)$ & $35(30)$ \\
\hline Female & $253(60)$ & $80(70)$ \\
\hline Tota 1 & 423 & 115 \\
\hline \multicolumn{3}{|c|}{ Age } \\
\hline $20-29$ & $65(15)$ & $16(14)$ \\
\hline $30-39$ & $192(45)$ & $46(40)$ \\
\hline $40-49$ & $119(28)$ & $38(33)$ \\
\hline $50-59$ & $38(9)$ & $12(10)$ \\
\hline $60-69$ & $9(2)$ & $3(3)$ \\
\hline \multicolumn{3}{|c|}{ Grade Level } \\
\hline Elementary $(\mathrm{K}-5)$ & $169(40)$ & $51(44)$ \\
\hline Middle & $80(19)$ & $30(26)$ \\
\hline$(9-12)$ & $174(41)$ & $34(30)$ \\
\hline \multicolumn{3}{|c|}{ Job Assignment } \\
\hline Certified Teachers & $423(61)$ & $98(85)$ \\
\hline Classified Employees & $248(36)$ & $7(6)$ \\
\hline Administration & $25(3)$ & $2(2)$ \\
\hline Spouses/Others & & $8(7)$ \\
\hline
\end{tabular}


end of December, 1982 , and is only approximate for any sperifiz date. The numbers for the participating groups were those that $f$ inished all tests and reports. Numbers in the table do not include the $14.8 \%$ who did not finish all requirements and were considered "dropouts." They do include 17 spouses, classified staff, and teachers from a neighboring school.

Despite the volunteer nature of the sample group, it is interesting to note that the percentage composition of the sample group and entire staff is almost the same for age, and varies within $10 \%$ for sex composition and gradelevel composition. Variations in age show a larger proportion of staff over 40 volunteering than under 40 (39\% of staff are over 40 years of age, $46 \%$ of the sample were over 40). Variations of grade level showed more elementary (K-8) personnel participating than high school personnel (59\% were elementary staff, $70 \%$ of sample were elementary). Classified employees composed $36 \%$ of the staff but only $7 \%$ of the sample was composed of classified employees. This was despite a determined effort to involve secretaries, cooks, groundskeepers, and aides. Administrators were proportionally represented and several more started, participated intermittently, but did not finish all tests. Certified teachers were the principal group participating, composing $85 \%$ of the total group. 
Comparison of Wellness Treatment Group and Control Group

The 24 staff members who were considered to be the control group were selected from the same schools and, therefore, were subjected to general inservices, announcements, informal discussions, and the pretesting and posttesting. Members of the group, however, did not at tend speakers regularly, did not make weekly reports of healthrelated behavior, and were not a part of any established support group. They "controlled" the formal aspects of the program while reflecting informal influences of the school, community, and national environments. The control group members were selected in the same manner as the larger treatment group; they were asked to volunteer initially and an effort was made to secure a representative sample from the volunteers. The control group members took the same pretests and posttests as the treatment groups. Table II compares the experimental groups and the control group. The demographic composition of the control group compared very closely to the treatment groups for sex, age, and grade level. A higher percentage of classified staf $f$ were in the control group and more staff members over 50 were controls. The total numbers, of course, were greatly different; experimental groups had 63 and 52 members, the control group had 24 . 
TABLE II

COMPARISON OF DEMOGRAPHIC CHARACTERISTICS OF TREATMENT AND CONTROL GROUPS OF GRESHAM WELLNESS PROGRAM

\begin{tabular}{|c|c|c|}
\hline Group & Treatment $(\%)$ & Control (\%) \\
\hline \multicolumn{3}{|c|}{ Sex } \\
\hline Male & $35(40)$ & $8(33)$ \\
\hline Female & $80(60)$ & $16(67)$ \\
\hline \multicolumn{3}{|c|}{ Age } \\
\hline $20-29$ & $16(14)$ & $2(9)$ \\
\hline $30-39$ & $46(40)$ & $9(38)$ \\
\hline $40-49$ & $38(33)$ & $7(29)$ \\
\hline $50-59$ & $12(10)$ & $6(25)$ \\
\hline $60-69$ & $3(3)$ & $0(0)$ \\
\hline \multicolumn{3}{|c|}{ Grade Level } \\
\hline Elementary $(\mathrm{K}-5)$ & $51(44)$ & $11(46)$ \\
\hline Middle & $30(26)$ & $5(21)$ \\
\hline$(9-12)$ & $34(30)$ & $8(33)$ \\
\hline \multicolumn{3}{|c|}{ Job Assignment } \\
\hline Certified Teachers & $98(85)$ & $18(75)$ \\
\hline Classified Employees & $7(6)$ & $4(17)$ \\
\hline Administration & $2(2)$ & $1(4)$ \\
\hline Spouses/Others & $8(7)$ & $1(4)$ \\
\hline
\end{tabular}


Participants who completed pre-treatment activities and signed contracts with goal statements but who did not complete weekly reports or did not take post-treatment tests and inventories were considered dropouts. (Participants who did not take pretests were not included in any group.) The dropout numbers and percentage rates are shown in Table III. (These numbers are not included in the previous numbers of participants.)

TABLE II I

DROPOUTS FROM GRESHAM SCHOOLS' WELLNESS PROGRAM

\begin{tabular}{lcccc}
\hline \multirow{2}{*}{ Grade Level } & & \multicolumn{3}{c}{ Status in Program } \\
\cline { 3 - 5 } Elementary & $(K-5)$ & 59 & Finished & Dropout (\%) \\
\hline Middle & $(6-8)$ & 31 & 53 & $(10.0)$ \\
High & $(9-12)$ & 42 & 29 & $(6.5)$ \\
\hline Total & & 132 & 115 & $(14.0)$ \\
\hline
\end{tabular}

Dropping out was usually the result of a conflict of other school reponsibilites during a successful football season and pre-Christmas programs. The physical fitness tests were difficult to make-up; missing the tests relegated the participant to dropout status for the project. The total dropout rate of approximately $15 \%$ compares favorably with other wellness program endeavors. Dropouts 
were not replaced.

Pre-treatment Status of Treatment and Control Groups

The large treatment group was divided into two subgroups for the purpose of testing one of the hypotheses of the study. Participants from one high school, one middle school, and five grade schools were assigned to Group L; the remainder (one high school, one middle school, and six grade schools) was assigned to Group $\underline{S}$. The control group was called Group C. The schools were randomly selected to be in one group or the other; all participants in each school were assigned to the same group. Treatment group memberships were approximately equal, 63 and 52 . Group comparisons of demographic characteristics as well as the means of pretreatment scores of the dependent variables are shown in Table IV.

Although the demographic characteristics of groups $\underline{S}$ and $\underline{L}$ show considerable varaiation, the mean scores on the pretreatment dependent variables are different by less than two percent in all cases. (As was noted earlier the composition of the control group was much the same as the combined treatment groups.) Group S had more male participants, more in older age groups, and fewer elementary teachers. The only variation of importance in pre-treatment means was the higher mental well-being score for the control group. 
TABLE IV

COMPARISON OF DEMOGRAPHIC AND PRE-TREATMENT CHARACTERISTICS OF TREATMENT AND CONTROL GROUPS OF GRESHAM WELLNESS PROGRAM

\begin{tabular}{|c|c|c|c|c|c|c|}
\hline \multirow[b]{2}{*}{ Demographic } & \multirow[b]{2}{*}{ groups } & \multicolumn{5}{|c|}{ Study Groups } \\
\hline & & $\underline{L}$ & & $\underline{S}$ & $\underline{C}$ & Total \\
\hline \multicolumn{7}{|c|}{ Sex } \\
\hline $\mathrm{Male}$ & & $15(24)$ & 20 & $(38)$ & $8(33)$ & $43(31)$ \\
\hline Female & & $48 \quad(76)$ & 32 & $(62)$ & $16(67)$ & $96(69)$ \\
\hline \multicolumn{7}{|c|}{ Age } \\
\hline $20-29$ & & $11(17)$ & 5 & $(10)$ & $2(9)$ & $18(13)$ \\
\hline $30-39$ & & $24(38)$ & 22 & $(42)$ & $9(38)$ & j5 (40) \\
\hline $40-49$ & & $19(30)$ & 19 & $(36)$ & $7(29)$ & $45(32)$ \\
\hline $50-59$ & & $6(10)$ & 6 & $(12)$ & $6(25)$ & $18(13)$ \\
\hline $60-69$ & & $3(5)$ & 0 & $(0)$ & $0(0)$ & $3(2)$ \\
\hline \multicolumn{7}{|c|}{ Grade Level } \\
\hline Elementary & $(\mathrm{K}-5)$ & $35(56)$ & 18 & ( 33 ) & $11(46)$ & $64(46)$ \\
\hline Middle & $(6-8)$ & $14(22)$ & 15 & $(29)$ & $5(21)$ & $34 \quad(24)$ \\
\hline $\mathrm{High}$ & $(9-12)$ & $14 \quad(22)$ & 19 & $(38)$ & $8(33)$ & $41(30)$ \\
\hline \multicolumn{7}{|c|}{ Means of Pre-Treatment Scores } \\
\hline \multicolumn{2}{|l|}{ Behavior } & 51.67 & \multicolumn{2}{|c|}{50.00} & 50.96 & \\
\hline \multicolumn{2}{|c|}{ Mental Well-Being } & 74.92 & \multicolumn{2}{|c|}{75.85} & 79.38 & \\
\hline \multicolumn{2}{|c|}{ Physical Fitness } & 47.14 & \multicolumn{2}{|c|}{46.83} & 45.96 & \\
\hline
\end{tabular}




\section{Assessment of Health}

All participants were asked to complete a nutritional intake inventory, a general well-being schedule, and a physical fitness test prior to setting goals and establishing contracts.

\section{Nutritional Intake Inventory}

The nutritional inventory was supplied by the Portland Adventist Medical Center and analyzed by their Health Services staff. Items were selected from the PAMC report that corresponded to the "Dietary Guidelines for Americans" (and to the practices stressed in this study) and compared for the three groups in Table V.

A comparison of the study group percentages with the recommended allowances of the "Dietary Guidelines for Americans" can only be done approximately since the categories from the survey do not match exactly.

1. Fat is recommended to supply $30 \%$ of the total diet; all study groups exceeded this by at least $10 \%$.

2. Natural sugars and complex carbohydrates are recommended to supply $48 \%$; total carbohydrate consumption in all study groups were $6 \%$ to $7 \%$ elow this figure.

3. Saturated fats are recommended to be $10 \%$ or less; $90 \%$ of the study groups exceeded this amount. 
TABLE V

PERCENTAGES OF TREATMENT AND CONTROL GROUPS FOLLOWING RECOMMENDED NUTRITIONAL PRACTICES PRIOR TO WELLNESS PROGRAM

\begin{tabular}{cccc}
\hline & \multicolumn{3}{c}{ Group } \\
\cline { 2 - 4 } Recommended Practice & $\underline{\mathrm{S}}$ & $\underline{\mathrm{S}}$ & $\underline{\mathrm{C}}$ \\
\hline Regular Breakfast & 40 & 45 & 60 \\
Variety of Food (\% of total diet) & & & \\
Proteins & 17 & 17 & 16 \\
Fat (30\%) & 42 & 41 & 43 \\
Carbohydrate (48\%) a & 41 & 42 & 43 \\
Restrict Fat/Cholesterol & & & 7 \\
Less than 10\% saturated fat & 1 & 5 & 40 \\
Less than 300 mg/day HDL & 37 & 46 & 53 \\
No Salt Added & 4 & 39 & 7 \\
Drink Water, 6-8 glasses/day & 21 & 14 & 53 \\
Drink less than 2 oz. alcohol/day & 39 & 40 & \\
\hline
\end{tabular}

a Recommendation was for natural or complex carbohydrates; survey was for total carbohydrate in take. 
4. Cholesterol is recommended to be $300 \mathrm{mg} /$ day; $54 \%$ to $63 \%$ of the study groups exceeded this amount.

5. No salt added is recommended; $45 \%$ of the participants were complying.

6. Water is recommended to be 6-8 glasses daily; 7-21\% of group did drink that much or more.

7. Alcohol, one or two drinks or less per day, was apparently exceeded by over one-half of the members of the study groups.

Individual and group summaries were returned and discussed with participants (as a group) by a nutritional specialist from Portland Adventist Medical Center prior to goal set ing.

Physical Fitness and Mental Well-Being Measurements

The results of the pretests of the dependent variables of the study were also reported and explained to the treatment groups by the PAMC specialist prior to goal set ting. Individuals were identified into levels of well-being based on their total score on the GWBS. Percentages at each level for the three study groups are found in Table VI. Fifty percent or more of each group was not experiencing "positive well-being"; over one-third of each group was deseribed as having stress problems or significant distress. Total score means of the treatment groups were less than one point, approximately one percent) apart, 
TABLE VI

COMPOSITION OF TREATMENT GROUPS AND CONTROL GROUP IN LEVELS OF WELL-BEING BEFORE AND AFTER THE GRESHAM WELLNESS PROGRAM

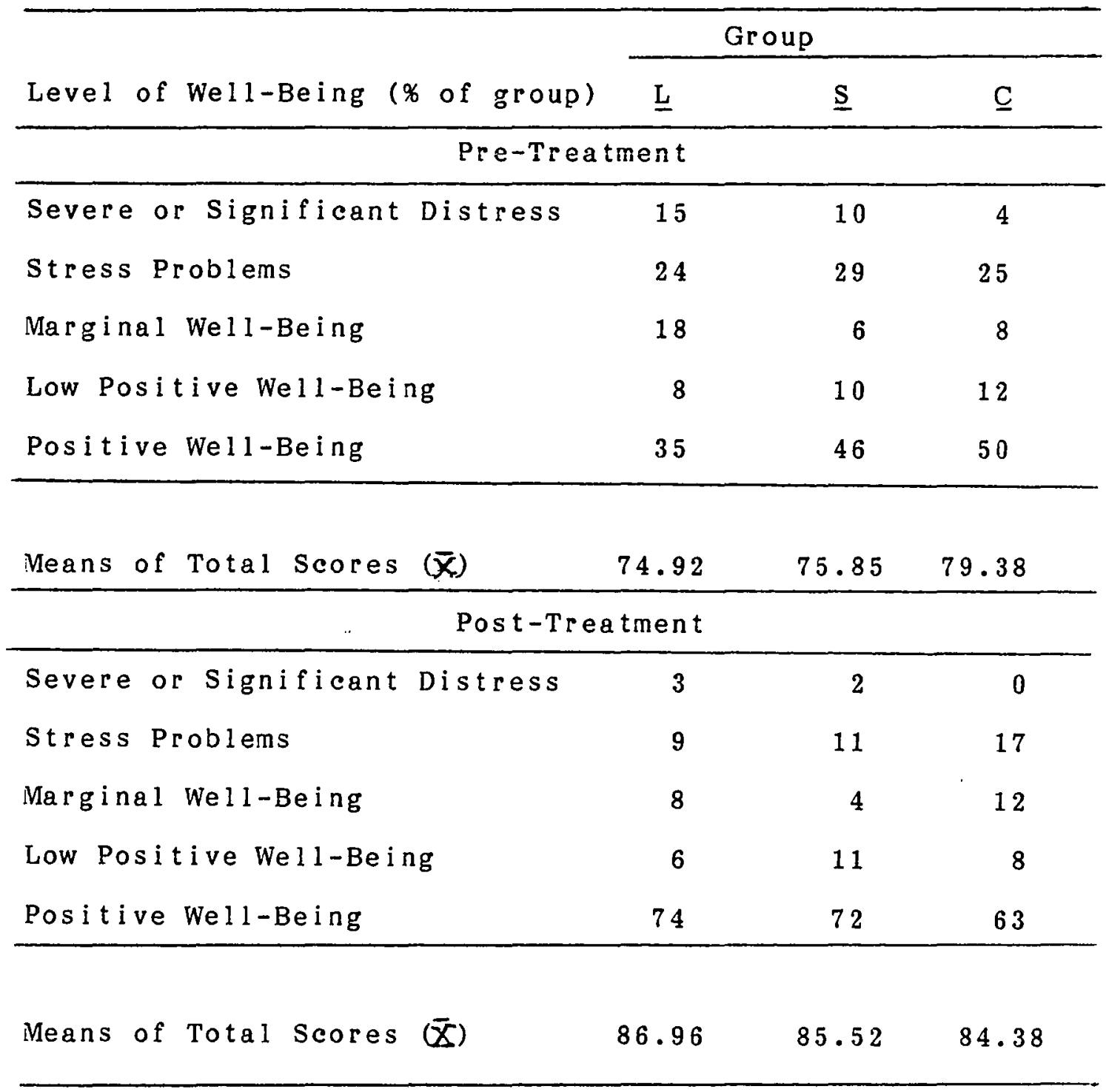


but the control group was $5 \%$ higher than that of the treatment groups.

The total physical fitness scores on the PAMC schedule were judged in five categories: poor, low, fairaverage, good, and excellent. The percentages at each level for the three study groups are found in Table VII. Twenty-five to thirty-six percent of the groups were below average and no one was judged excellent. The means of total scores and the distribution of scores were similar for the three groups.

\section{Health-Related Behavior Reported by Participants}

Treatment and control group participants were asked to report their typical health-related behavior for the month preceding the assessment. The report form, supplied by the director, awarded points for performing designated health practices each week. A total score was determined and used as an index of pre-treatment health-related behavior. Treatment groups continued weekly reports to the project director on the same form throughout the eight-week program. At the end of the program, each participant used the accumulated reports to estimate an average sustained participation level. Estimates were made by graphing the eight separate levels and drawing a "best fit line" (excluding one extreme score). This estimate of the data was checked by the program director and a "sustained health- 
TABLE VII

COMPOSITION OF TREATMENT GROUPS AND CONTROL GROUP IN LEVELS OF PHYSICAL FITNESS BEFORE AND AFTER THE GRESHAM PROGRAM

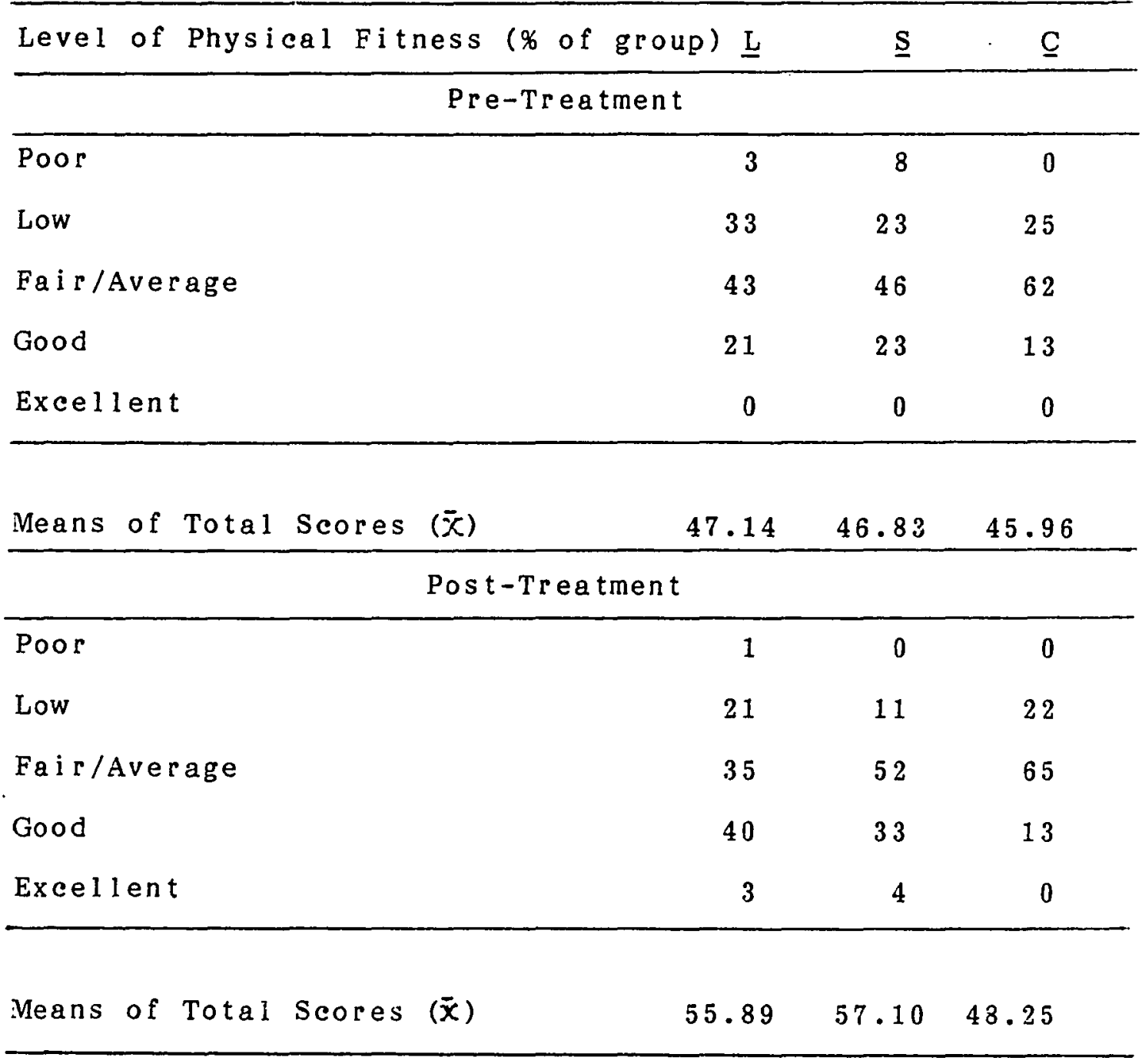


related behavior score" established for each individual. Members of the control group were asked to estimate a total score average for the eight weeks period, using the same criteria. A comparison of pre-treatment and sustained behavior mean scores for all three groups follows:

1. Behavior levels, pre-treatment, were almost identical--L, $51.67 ; \underline{\mathrm{S}}, 50.00 ; \underline{\mathrm{C}}, 50.90$.

2. Treatment groups sustained almost identical

levels with resulting similar increases--L, 73.73 , increase of $22.06 ; 5,72.31$, increase of 22.31 .

3. Control group sustained a 52.38 level for a 1.42 increase.

Degree of Participation in Type of Health Behavior

The weekly report contained 20 subseales that were grouped in categories of exercise, nutrition, stress management, and avoiding harmful habits. A summary of the degree of participation in each of these categories is shown in TABLE VIII.

According to the reported data, physical exercise was the most difficult wellness practice to maintain over the eight-week period and avoiding harmful habits and nutritional practices were the easiest. Perhaps an explanatory factor is that the nutritional and stress practices were easier to judge as attained; "less salt" is less specific 
than "exercise 20 minutes at target heart rate."

TABLE VIII

SELF-REPORTED LEVELS OF PARTICIPATION IN WELLNESS BEHAVIORS BY TREATMENT GROUPS IN GRESHAM PROGRAM

\begin{tabular}{|c|c|c|c|}
\hline \multirow[b]{2}{*}{ Category of Behavior } & \multicolumn{3}{|c|}{ Level of Participation (\% of group) } \\
\hline & Low & Middle & $\mathrm{High}$ \\
\hline Physical Exercise & 30 & 41 & 29 \\
\hline Nutritional & 3 & 33 & 64 \\
\hline Stress Management & 6 & 35 & 59 \\
\hline Avoiding Harmful Habits & 6 & 14 & $80>$ \\
\hline
\end{tabular}

Each participant also reported his/her type of physical exercise. Data from weekly reports provided type of exercise and frequency of times named that is summarized in Table IX.

\section{TABLE IX}

TYPES OF PHYSICAL EXERCISE AND RELATIVE FREQUENCY REPORTED BY PARTICIPANTS IN GRESHAM WELLNESS PROGRAM

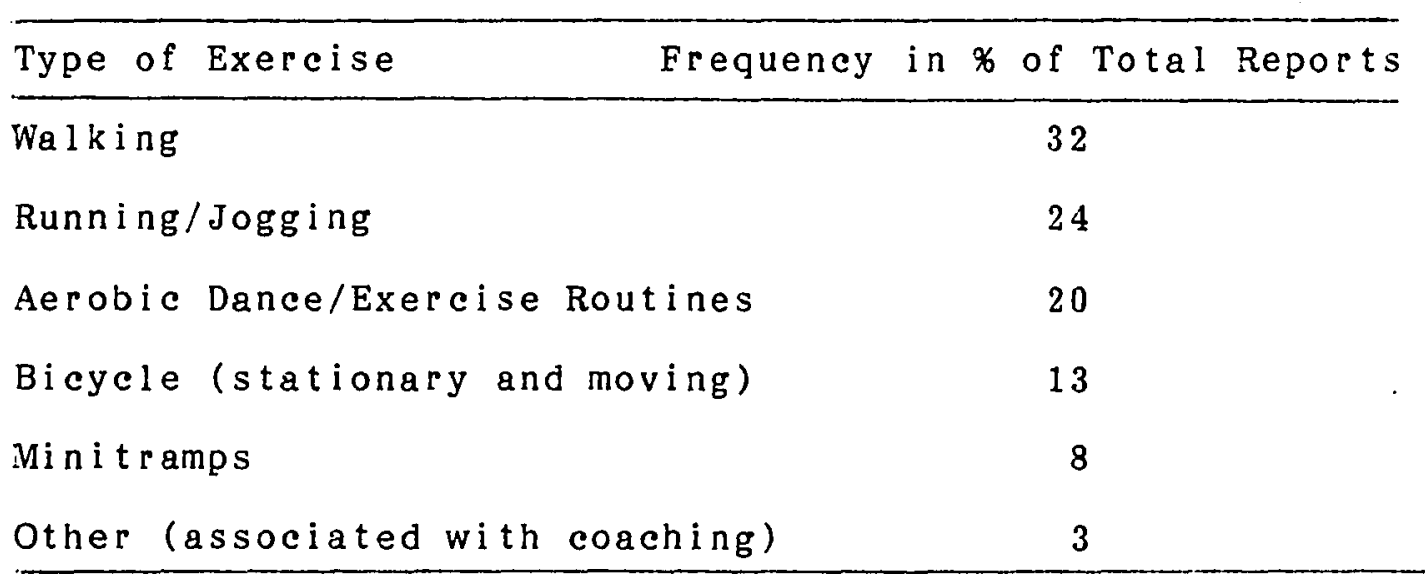


The most often reported exercise was walking, alhough it was often included with other forms of exercise. Running and jogging was the second category most reported. Aerobic exercise and aerobic dance (third) meant organized group activities. A number of participants found minitramps (rebounders) preferable to being out-of-doors during the rain-filled fall and winter days.

Barriers and Resources Reported by Participants

Further indication of the type of treatment comes from a summary of the "barriers" and "resources" reported by participants in the weekly reports and final summary. At the end of the treatment period, participants were given their accumulated weekly reports and asked to prioritize a 1 ist of resources which they found most useful in maintaining their programs and to similarly rate a list of barriers and obstacles. Categories of resources offered were: weekly reports, speakers, charting progress, designated support group, other support at school, and family support. Categories of barriers offered were: other people, lack of time, lack of knowledge, lack of motivation (drive), and lack of facilities. Rankings are summarized in Table $x$.

The greatest resource reported was the speakers provided. Speakers were recognized authorities in their fields and carefully selected to match the goals of the 
TABLE X

BARRIERS AND RESOURCES TO MAINTAINING INDIVIDUAL CONTRACTS REPORTED BY PARTICIPANTS IN GRESHAM WELLNESS PROGRAM

\begin{tabular}{ll}
\hline Support & Priority Ranking (greatest to least) \\
\hline Resources & 1. Speakers \\
& 2. Weekly Reports \\
& 3. Charting \\
& 4. Family Support \\
& $5 . \quad$ Designated Support Group \\
& 6. Informal Support at School \\
Barriers & 1. Lack of Time \\
& 2. Lack of Drive \\
& 3. Other People \\
& 4. Lack of facilities \\
$5 . \quad$ Lack of Knowledge
\end{tabular}


class. Attendance for speakers was in excess of $85 \%$ of the group, despite numerous conflicts. Weekly reports were named as second most important. These reports had been carefully monitored, frequent reminders and calls for late reports produced almost $100 \%$ return. Bi-weekly newsletters reinforced the prompt reporting. Charting of progress, third in importance, was introduced by a pretreatment speaker and charts (graphs) were prominently displayed in all schools throughout the eight weeks. Designated support groups were not reported as important as family support. Members found support from friends who were not in the class but were often encountered in the work day. Lack of time was the greatest barier reported. Lack of drive (reported second among obstacles) included failure to resist the temptations of Thanksgiving, dinners out, and vacations. The barrier of "other people" (reported third) was occasionally mild ridicule; more often it was from well-meaning relatives and $f r i e n d s$ who did not agree with the importance of the wellness concept. Lack of knowledge was reported as the least barrier. There were no differences in the rankings of Groups $\underline{S}$ and $\underline{L}$.

Knowledge Test

Participants were told in the beginning class that a final test would be given to help determine credit and grades for the course. Text assignments, the content of 
the speakers' lectures, and the procedures used in the course were the targets of the test. The test was considered part of the treatment and not as a dependent variable of the experiment. Test items were designed by the project director to determine attendance and achievement in the course rather than to measure global principles of wellness. Members of the control group took the knowledge test at the time of posttesting. They had not been forewarned that it would be given to them. Average scores for the three groups were: Group $\underline{L}--83 \%$ correct; Group $\underline{S}, 82 \%$

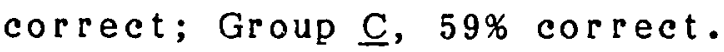

Improvement of Physical and Mental Health Factors

Post-treatment physical fitness tests and a selfreported general well-being schedule gave individual scores and group means that were compared with pretreatment data and means for degree of improvement. A $t$-test for.dependent groups was used to compare pre-treatment and posttreatment results in both physical and mental factors for each of the three groups. Table XI displays these comparisons.

Both physical and mental factors were improved significantly at the .05 level for both treatment groups. The only significant improvement by the control group was in mental well-being $(.05$ level). 
TABLE XI

$t$-TEST COMPARISON OF PRE-TREATMENT AND POST-TREATMENT MEANS OF PHYSICAL AND MENTAL WELL-BEING SCORES OF WELLNESS GROUPS

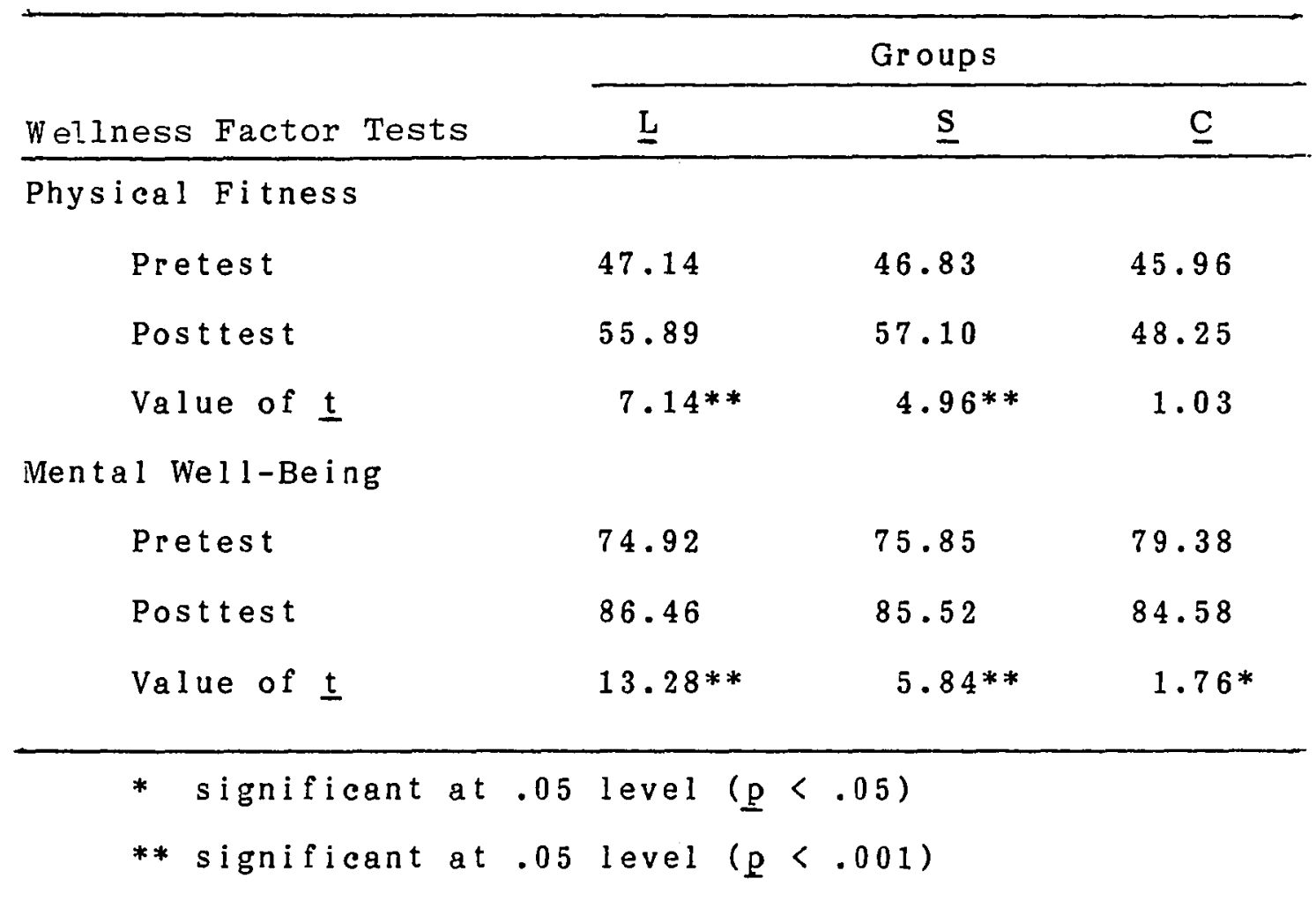


Change in Physical Fitness Subtests

The individual tests that composed the physical fitness battery were (1) weight, (2) percent of body fat, (3) grip strength (measured in kilograms), (4) flexibility in stretching hands toward toes (inches), (5) number of situps in 60 seconds, (6) resting pulse rate, (7) systolic and diastolic blood pressure, and (8) maximum oxygen consumption measured with a "step test." Each individual's change was computed and an average change determined for the group. Table XII shows the changes expressed in units of measurement and in percentages.

The most pronounced gains during the eight week period were in (1) body strength as measured by sit-ups and grip strength, (2) maximum oxygen consumption as measured by the step test, and (3) flexibility. Pulse rates and blood pressure showed smaller gains. Least improved was the percent of body fat (where there was a $1.0 \%$ increase-the control group showed a $1.4 \%$ increase.)

\section{Correlation of Behavior and Health Factors}

Pearson product-moment correlation coefficients were calculated for selected pairs of measured or change scores where there was an interest in the relationship. The high correlations between pretest and posttest scores of the same factor bears out an expectation that individuals would keep the same relative position among other participants in 
TABLE XI I

AVERAGE CHANGES FROM PRE-TREATMENT TO POST-TREATMENT MEASUREMENTS OF PHYSICAL FITNESS SUB-TESTS I N GRESHAM WELLNESS PROGRAM

\begin{tabular}{|c|c|c|c|c|c|}
\hline \multirow[b]{2}{*}{ Sub-Tests } & \multicolumn{3}{|c|}{ Group } & \multirow{2}{*}{\multicolumn{2}{|c|}{$\underline{\mathrm{C}}$}} \\
\hline & $\underline{L}$ & & $\underline{\mathbf{S}}$ & & \\
\hline We ight, pounds $(\%)$ & -2.3 & $(1.6)$ & $-2.1(1.5)$ & 1.6 & $(1.1)$ \\
\hline Body Fat, $\%$ weight $(\not)$ & 1.5 & $(6.3)$ & $.6(2.5)$ & 1.4 & $(6.0)$ \\
\hline Flexibility, inches, $(\%)$ & 1.3 & $(10.3)$ & $1.2(9.6)$ & .5 & $(4.0)$ \\
\hline Grip Strength, $\mathrm{kg},(\%)$ & 4.0 & $(5.7)$ & $5.4(7.3)$ & 2.8 & $(4.0)$ \\
\hline Sit-ups in 60 sec. $(\%)$ & 6.6 & $(25.0)$ & $5.9(22.4)$ & 1.0 & $(3.8)$ \\
\hline Resting Pulse Rate(\%) & -3.0 & $(4.1)$ & $-1.0(1.4)$ & .7 & $(0.9)$ \\
\hline Blood Pressure,Sys. (\%) & -5.2 & $(4.4)$ & $-2.2(1.9)$ & -3.9 & $(3.3)$ \\
\hline Blood Pressure,Dia. (\%) & -2.2 & $(2.8)$ & $-1.5(1.9)$ & $-2 \cdot 9$ & $(3.7)$ \\
\hline Maximum Oxygen Con.(\%) & 2.0 & $(6.2)$ & $2.2(6.9)$ & .9 & $(2.8)$ \\
\hline
\end{tabular}


the same test given before and after treatment. (See Table XI (I)

The relationships between health-related behavior and mental well-being also appear in Table XIII. There is a significant correlation between the level of sustained health-related behavior and the level of mental well-being. There was a significant correlation between the change in behavior and the change in mental well-being. But, no significant correlation between level of behavior and change in general well-being was found.

The relationships between health-related behavior and physical fitness is shown in Table XIII. The only significant relationship was between the change in behavior and the change in fitness. Relationships between the level of sustained behavior and either the post level of physical fitness or the change in physical fitness were not found. Comparisons of mental well-being and physical fitness reveal positive correlations but only one of statistical signifigance (change in well-being and post physical fitness).

In summarizing the relationships of health-related behavior, general well-being, and physical fitness, (1) the strongest relationships ( $\underline{p}<.001$ throughout) are between pre- and post-treatment scores in the same test; (2) the second most consistent relationships are those between changes in behavior and changes in physical fitness and 
TABLE XI II

PEARSON PRODUCT-MOMENT CORRELATION COEFFICIENTS BETWEEN HEALTH FACTORS IN GRESHAM WELLNESS PROGRAM

Factors Correlated Combined Treatment Groups, $\mathrm{n}=115$

Pre and Post of Same Factor

Mental Well-Being

$.445 * * *$

Physical Fitness

$.762 * * *$

Behavior and General Well-Being

Sustained Behavior/Post GWB

$.392 * * *$

Sustained Behavior/Change GWB

.088

Change Behavior/Change GWB $.290 * *$

Behavior and Physical Fitness

Sustained Behavior/Post Fitness

$-.050$

Sustained Behavior/Change Fitness

.188

Change Behavior/Change Fitness

$.224 *$

General Well-Being and Physical Fitness

Post GWB/Post Fitness

Post GWB/Change Fitness

.159

Change GWB/Post Fitness

$.230 *$

Change GWB/Change Fitness

.186

* Significant at .05 level; $(\underline{P}<.05)$

** Significant at .05 level; ( $\underline{p}<.01)$

*** Significant at .05 level; ( $\underline{\mathrm{p}}<.001)$ 
changes in mental well-being. (Change of factors are apparently more related than level of factors.) There is no pattern of significant relationships between physical fitness and mental well-being.

Comparison of Post-Treatment Levels of Group Means

The post-treatment means of the experimental groups $\underline{L}$ and $\underline{S}$ were compared separately with the means of the control group using the Dunnett method (Winer, 1962, p. 89). Further, the means and error terms were adjusted with corresponding pre-treatment means. The results are shown in Table XIV. Group $\underline{L}$ was significantly different from the control group for mental well-being (.05 level). Group $\underline{S}$ was significantly different for physical fitness $(.05$ level) although the mental well-being $t$ was positive.

The post-treatment means of the $\underline{L}$ and the $\underline{S}$ groups were compared with a t-test with means adjusted with pretreatment means. There was no significant difference in either the means of the physical fitness scores of the two groups or of the means of the general well-being scores. Based on these findings we are unable to say that the providing of a leader to organize support made any difference in the performance of the two groups. 
TABLE XIV

DUNNETT $t$-TEST OF PHYSICAL FITNESS AND WELL-BEING MEANS (ADJUSTED TO PRETESTS) OF GRESHAM WELLNESS PROGRAM

\begin{tabular}{llcc}
\hline & \multicolumn{3}{c}{ Group } \\
\cline { 2 - 4 } Statistic & L & S & C \\
\hline Adjusted Means, Well-Being & 87.05 & 85.62 & 82.63 \\
Adjusted Means, Fitness & 55.68 & 57.10 & 49.20 \\
Dunnett $t$ & & & \\
\multicolumn{1}{c}{ Fitness with Control } & 2.05 & $2.50^{*}$ & \\
Well-Being with Control & $2.37^{*}$ & 1.46 & \\
\hline
\end{tabular}

* Significant at .05 level 
CHAPTER V

GENERALI ZAT ION, RECOMMENDATIONS, AND FURTHER STUDY

This chapter will review the need (that led to the project) and the results, generalize from the conclusions and relationships established in Chapter IV, and make recommendations for further study in wellness programs.

\section{Summary of the Study and Results}

Need for Wellness Lifestyle

Business, education, and government leaders are advocating a change in 1 ifestyle for Americans that they believe will lengthen and improve the quality of 1 ife. This recommendation is based on a change in the causes of death (overconsumption, stress, and lack of exercise) and a redefinition of health care (wellness: promotion and prevention, not treatment). Despite the evidence of research and a growing involvement in exercising and dieting, a majority of Americans are acting on misinformation or an ingrained 1 ifestyle which increases the $r$ isk to their health.

Public schools can help bring about the desired wellness lifestyle by teaching principles and skills of good health and modeling appropriate behavior. Presently, typical school staffs are not properly prepared to do this. Further, the typical staff is affected by the same faults 
of lifestyle as the general public, which reduces their job productivity and the cost to school districts of maintaining their health.

\section{Study Revi ewed}

This study attempted to identify the elements of an effective staff development program that would motivate a school staff to teach a wellness curriculum and improve their own mental and physical health. The sample was $23 \%$ of the certified staff of 448 in a school district that had higteschools, middle schools, and elementary schools. It was a volunteer group. Total staff age groups were proportionally represented, but $10 \%$ more females participated than an exact proportion and $11 \%$ more grade school teachers.

One hundred and thirty-two participants were asked to write contracts (14.8\% subsequently dropped out) aimed at goals in physical fitness through exercise and nutrition, stress management, and the reduction of harmful habits. Participants were preassessed for nutritional practices, physical fitness, mental well-being, and health-related behavior. They participated in an eight-week program making weekly reports of their activities to a project director. Speakers, reading assignments, and the report form provided advocated an integrated program of exercise, nutritional practices, and stress control measures, but 
participants were free to choose the exact form of the practice. Their reports indicated that walking, running and jogging, and aerobic dance were the exercises used $76 \%$ of the time. Thirty percent of the group, however, exercised below the recommended minimum level. For some, more points were earned through ways other than exercise. Posttests were given for physical fitness and mental wellbeing. The program treatment consisted of the assessment of health, contracting of activities, weekly reports, speakers and reading assignments, charting progress, and designated support groups. Participants ranked speakers, weekly reports, and charting as more helpful than designated support groups. They ranked lack of time and lack of personal drive as greater barriers than a lack of knowledge or facilities. A control group of 24 teachers from the same schools were proportionally matched with the total certified staff for grade level, sex, and age (slightly more older individuals were in the control). Since a general enthusiasm for wellness activities pervaded the schools, the control was for the formal program only.

Results of Hypotheses Testing

Hypotheses were tested in three general areas from which generalizations were made: (1) the effect of the twelve-week program in producing significant changes in mental and physical health; (2) relationships in the study 
between behavior and health factors and relationships between mental and physical health; and (3) the effect of providing leaders for support compared to support without leaders. All hypotheses were tested at the .05 level.

The program produced significant changes in mental and physical health, whereas the informal influences on the control group produced no significant change in physical fitnss and a significant change (but to a lesser degree) in mental well-being. The Dunnett $t$-test, that compared means of final physical and mental tests (adjusted with pretest means) showed a significant difference between the leaderled groups (Group L) and the control group for mental well-being and a sigrificant difference for the leaderless

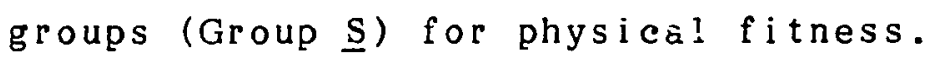

Clearly the program had a pronounced effect on the treatment groups that could not be explained by chance or by informal influences in the school, community or national environment. The significant increase in the control group in mental well-being may have been due to informal influences in a school environment where wellness was being stressed.

The second hypothesis that predicted significant relations between health-related behavior and health factors was realized between behavior level sustained for eight weeks and the mental well-being level and change. However, sustained behavior was not related to the final level of 
physical fitness, nor, to the same degree, in a change in physical fitness. There was no pattern that consistently related physical fitness and mental well-being. Evidently, mental well-being was associated with the degree of involvement in the activities rather than the state of physical health.

The third hypothesis that predicted a significant effect of providing leaders to the support groups was not indicated in the knowledge, physical fitness, mental wellbeing test nor level of sustained behavior. They were all very much the same, well within the probability of chance. There were some advantages of management and planning but they did not result in significant changes in the dependent variables of the study.

\section{Patterns Among Test Results}

The study was centered around a staff development program performed as a college course to demonstrate the value of a model that could be used by other school districts. As a model it enjoyed several advantages that may pose limitations to others attempting to duplicate the project or to those generalizaing from the data collected.

\section{Limitations of the Study}

(1) The sample was composed of volunteers and, although age, sex, and grade level were proportionally re- 
presented, the sample undoubtedly was not typical for interest in the subject and in physical condition or need. Any attempt to generalize from the data should be to volunnteers.

(2) The program had the advantage of excellent speakers and the help of nearby medical centers. These advantages may not be available to the same extent in all areas.

(3) The study was done at a time of growing national interest in wellness activities; newspaper and TV coverage produced a stimulation and excitement that may not always be available.

(4) The program has a large number of identifiable characteristics, each of which is variable to some degree. For example, an individual could earn a high score for health-related behavior in quite a different way than another. Yet, they both would be compared for improvement in physical fitness. This presents no problem if total physical fitness scores and total behavior scores are analyzed; sub-test scores, however, must be examined in a more speculative manner--for possible explanations or for clues to further investigation.

Physical Fitness Tests, Patterns, and Recommendations

The data support conclusions that the program was successful in changing the total fitness score, however, 
not all sub-test scores were improved and those that were improved were not improved to the same degree. Several factors may account for the uneven changes. Time Required for Change. Concern that an eightweek program (actual record-keeping period) would not be enough time to allow physical changes to occur was not true for the total score nor for strength and endurance ( $25 \%$ change), flexibility ( $10 \%$ change), and maximum oxygen consumption ( $6.5 \%$ change). There were marginal changes in pulse rate (less than 5\%) and body weight (less than $3 \%$ ). There was an actual increase in percent of body fat (5\%) in all groups (including the control group).

Two logical explanations of the differing degrees of improvement in physical sub-test scores are: (1) the program strategies are not equally effective with all factors; (2) some factors are slower to change. Health literature review suggests the latter is true for body composition. Bailey (1977) wrote that some body composition reversals and blood chemistry changes take "months, perhaps years" (p. 101). It would appear, then, that strength and endurance, flexibility and oxygen comsumption (aerobic health) are easier to change in programs of this nature. Programs designed to change body composition might well plan treatment periods greater than eight weeks.

Means and Distribution of Total scores. The means 
and the distribution of physical fitness total scores are better indicators of the effect of the program since all participants were striving for an increase in some aspect of the total score whereas they were not all aiming at all sub-test scores. Means of total scores differed significantly (Table XI) between pre-treatment and post-treatment measurements. The final distribution of physical fitness total scores are compared with the initial distribution us ing PAMC norms (see Table XV).

TABLE XV

DISTRIBUTION (PERCENT OF GROUP) OF TREATMENT GROUP IN CATEGORIES OF PHYSICAL FITNESS

\begin{tabular}{lccccc}
\hline Testing & Poor & Low & Average & Good & Excellent \\
\cline { 2 - 6 } Pre & 5 & 28 & 44 & 22 & 0 \\
Post & 1 & 17 & 42 & 37 & 3 \\
\hline
\end{tabular}

The Gresham teachers group initially were slightly lower than the PAMC norming group. After the program there was a shift at every level toward greater health. The final percentages show the group somewhat above the norming group.

Difficulties of Fitness Measurements. At tempts were made to use the same personnel for measurements through the three days of pretesting and the three days of posttesting. Supervising personnel from PAMC and Mt. Hood Community 
College Allied Health Division assisted in establishing exact procedures for each sub-test. Nevertheless, some recommendations can be made. Some physical factors (flexibility, strength, aerobic, body composition) are quite stable while others vacillate with the time of day, degree of stress immediately preceding the test, and the season (blood pressure, pulse rate). With some tests, the technique of measurements are extremely variable (skin-fold test for body fat) while others are difficult to mismanage (number of sit-ups in 60 seconds). Particular attention to the standardizing of procedures and measuring at the same time of day (and week) is more important for some tests than for others. The ill effect of errors in messuring is not only to produce a greater variation in the data but to discourage participants. A control group is very important not only to guard against seasonal changes (the weight and body fat averages increased with holidays and winter months), but also to guard against systematic mistakes in measurement (many participants were convinced that posttreatment skin-fold tests were done with a new technique).

Mental Well-Being Measurements, Distributions

Sub-tests of the GWBS were not used in the study; pre-treatment and post-treatment means (of total scores) showed significant differences at the .05 level $(\underline{p}<.001)$ for both treatment groups. The control group also showed a 
significant increase $(\underline{p}<.05)$. When post-treatment GWBS means were compared, Group L was significantly different from the control group, but Group $\underline{S}$ was not. The final distribution of mental well-being scores were compared with the initial distribution by using norms accompanying the GWBS (Table XV)

TABLE XVI

DISTRIBUT ION (PERCENT OF GROUP) OF TREATMENT GROUP IN CATEGORIES OF MENTAL WELL-BEING

\begin{tabular}{lcccccc}
\hline \multicolumn{2}{c}{ Distress } & Problems & Marginal & Low & Positive & Positive \\
\hline Pre & 12 & 26 & 13 & 9 & 40 \\
Post & 3 & 10 & 6 & 8 & 73 \\
\hline
\end{tabular}

The data reveal that, initially, less than half the Gresham teachers' sample group enjoyed positive well-being and $40 \%$ exhibited distress or problems. The posttreatment scores showed a strong movement to more positive well-being. The effect of the formal program (See Table $X V I$ ) is more accurate when compared to the similar data for the control group (Table XVII)

\section{TABLE XVII}

DISTRIBUTION (PERCENT OF GROUP) OF CONTROL GROUP IN CATEGORIES OF MENTAL WELL-BEING

\begin{tabular}{lccccc}
\hline Distress & Problems & Marginal & Low & Positive & Positive \\
\hline Pre & 4 & 25 & 8 & 12 & 50 \\
Post 0 & 17 & 12 & 9 & 62 \\
\hline
\end{tabular}


There was, again, a shift to more positive well-being. Treatment groups showed a post-treatment increase in the top two categories of well being of $64 \%$; control group, a corresponding increase of $15 \%$. Apparently, there was a pronounced positive effect of the formal program. Whether the effect is due to specific stress control activities, improved physical fitness, or the stimulation of working on a project with a group of associates cannot be determined with these data alone. The significant improvement of the control group argues for a more general cause; the greater increase of the treatment groups argues for greater particiapation or increased physical fitness. To further investigate potential causal relationships, correlation coefficients were calculated (Table XIII).

Relations of Physical, Mental, and Behavioral Factors

The significant correlations between the level of sustained behavior and the final state of mental well-being indicated that those who maintained a high level of participation had a correspondingly high level of mental well-being. Sustained behavior, however, had almost zero correlation with final physical fitness levels. This suggests that persons low in fitness made a high level sustained effort but did not attain a high level of fitness. This is compatible with the significant correlation of "change in behavior" with "change in fitness". Physical 
fitness and mental well-being were not signicantly related. It is possible that well-being is caused by a number of factors, including physical fitness--but also participation and the excitement of a new project--and, therefore, they are not "correlated".

These may very well be only short-range effects; sustained health-related behavior, given enough time, should certainly produce physical fitness; the euphoria reported by "fit" athletes argues for that relationship. However, the results of this investigation point to a short term increase in mental well-being associated with changed and sustained behavior, not necessarily resulting in being more physically fit.

Comparison of the Treatment Groups

The $t$-test comparing mean scores showed no significant difference on the dependent variables of the experiment for the leader-led (Group L) and the leaderless (Group S) groups. Group $\underline{S}$ had been organized into small support groups without a designated leader; Group L were larger groups with an appointed leader. Leaders were selected by the project director on the basis of health education, leadership qualities, and demonstrated interest in the project. Most leaders organized some form of exercise groups and regular meetings. All leaders were directed to sign the weekly reports, reinforce gains, suggest solutions 
to problems, and encourage sharing among group members. They were compensated for these services. Smaller support groups were asked to meet each week and to do the same things without a leader. Despite the energy and apparent good organization shown by most of the leaders, the t-test comparison of means (adjusted for pretests) showed that the accomplishments of their charges were not significantly different in any of the dependent variables of the study.

Two explanations have been of fered by the management group of the project for the lack of difference in the improvements of the two experimental groups. One explanation is that other factors overshadowed the importance of the support group. Speakers, charting, weekly reporting were ranked by the participants as more important than the designated support group. Support from home and friends also was 1 isted as more important than the designated group. While participants extolled the value of the support of the class and "others", the support was not limited to one. identifiable source. Some of the more valuable support groups arose spontaneously among acquaintances in car pools, lunch companions, break-time associates, or people who daily passed in the hall. It is possible that participants should form their own support groups and not limit the membership to students in the class.

A second reason was the resourcefulness of teachers who, not being assigned a leader, were often quite capable 
of sharing the leadership chores or appointing a leader of the i $r$ own.

Despite the lack of significant differences in measured variables, schools with designated leaders were better organized with meetings, more coordinated with reports and contributed more to planning and management. To further test the value of a leader-led support group could be done with these changes:

1. Greater direction and training for the leaders to insure the repetition of a single procedure

2. Greater isolation of experimental groups to prevent the contamination of treatment.

\section{Further Study}

The thesis of this study is that an integrated program of nutrition, exercise, and stress control would produce significant changes in mental and physical health. Some obvious targets for further study can be suggested by narrowing the independent variables. Other suggestions arise by lengthening the time period of experimentation, and by further exploring some of the relationships and applications only tenuously shown in the present study.

Fewer Variables

(1) One of the components (nutrition, stress, or exercise) could be omitted in one treatment and the results 
compared with a wholistic group's gains. Repetitions of this sort of experiment could aim at establishing the relative importance of the components of the integrated program.

(2) One of the components could be selected as the only independent variable (all else controlled) and the effects on mental and physical factors compared. (This is contrary to the wholistic thesis but has the advantage of specificity.)

\section{Longer Time Period}

The changes in 1 ifestyle that would reduce health risks can only be hypothesized for the individuals that sustained a twelve-week program. Sustaining a program for a longer period of time would be more convincing. Further, some of the purported benefits of an integrated exercisenutrition program (e.g., body fat composition) were not realized in the short time period. Mental well-being gains seem to be related more to the change in behavior than to any improved level of physical fitness. This, too, may be a short range effect.

Mind/Body Connection

The experiences of participantsd in exercise prograns currently being promulgated by speakers and the press suggest a greater relationship between the improvement of mind. and body than the data of this study will support. How- 
ever, other factors may have obscured the importance of this connection in the short-term program.

Another aspect of the mind/body connection is the negative effect of extolling the athletic image to individuals who may have inherited a "set point" (Tucker, 1982) that tends to return body weight to a predetermined (overweight) status despite dieting efforts. It may be more important for a person's mental health to accept a reasonable present health level than striving for higher levels that are very difficult, if not impossible, to attain.

\section{Combatting Burnout}

Although the causes for the improvement of mental well-being are not clear from the study, there was a dramatic improvement in the experimental groups and a significant change in the control group on the GWBS. Unsolicited comments from participants described the excitement of a group project and the gratitude of a district supported program aimed at their personal welfare. Public displays of progress charts, common testing and exercising groups, as many as two hundred people at meetings where testimonials, sharing, and good input programs brought people together in an agreeable environment for a definite purpose. These factors may have been more important to the mental health of the staff than the subjects that were the targets of program. 


\section{REFERENCE NOTES}

1. Conners, W. E. Safeway Conference on Nutrition, Portland Oregon, March, 1983.

2. President's Council on Phyical Fitness and Sports. Fitness in the workplace. Distributed by Phillips Petroleum Company.

3. Hopper, W. R. Safeway Conference on Nutrition, Portland, Oregon, March, 1983.

4. Health Skills for Life, Eugene $4 \mathrm{~J}$ Schools, Eugene, Oregon.

5. North Clackamas Health Guide, North Clackamas School District, Milwaukie, Oregon.

6. Project Prevention Health Materials, The Dalles Schools, The Dalles, Oregon.

7. North Florida Regional Hospital. Health Promotion: I tems and Topies, Gainsville, Fla.

8. Portland Advent ist Medical Center, Health Services Division. Portland, Oregon.

9. Mal inow, M. R. Safeway Conference on Nutrition, Portland, Oregon, March, 1983.

10. Stevens, V. J. Channel 2 TV broadcast, Portland, Oregon, September 6,1983 .

11. Project Leadership Materials, Association of California School Administrators, Norwalk, California.

12. Conrad, C. C. Do we have the desire and determination to promote physical fitness for all? Remarks to first international conference on physical fitness and sports for all, May, 1980 .

13. Taylor, J. F. Conquering 1 ife's tensions. The Subscriber, distributed at Seaside Health Conference, Seaside, Oregon, 1982 . 


\section{REFERENCES}

American Hospital Association. Self-help groups: the untapped health promotion resource. Promoting Health, $1982,3,(4), 1-7$

Ardell, D.B. High level wellness. Emmaus, Pa.: Rodale Press, 1979 .

Arde11, D. B. 14 days to a wellness 1 ifestyle. Blithedal Ie, CA.: Whatever Pulishing, Ine., 1982 .

Ardell, D.B., \& Tager, M.J. Planning for wellness. Portland, Or.: Wellness Media Ltd, 1981.

Argeropoulos, J. Taking responsibility for your health. HSA National News, 1981 , May.

Bailey, Covert. Fit or fat. Boston: Houghton, Mifflin Company, 1978 .

Bauer \& Robinson, L.M. High level wellness for corporate executives: a program design, Journal of Health Care Marketing, 1982, 2 (1), 37-45.

Beck, K.H. Understanding motivation on plaque control, Health Education, $1982,13,38-41$.

Berry, A. Good health for employees and reduced health care costs for industry. Washington, D.C.: Health Insurance Association of America, 1981.

Blue Cross of Oregon. The good life, it can kill you. Port land, Or.: 1981 .

Breslow, L., \& Somers, A.R. The lifetime health monitoring program. New England Journal of Medicine, 1977, 296, $601-608$.

Canadian Minister of Supply and Services. Standardized test of fitness, assessment report. Toronto, Canada, 1979 .

Caplan, R.D. Adhering to medical regimens: pilot experiments in patient education and social support. Ann Arbor, Mich.:, 1976 .

Company fitness program, a good investment. Employee Health and Fitness, $1981,3(10), 113-\overline{115}$. 
Drolet, J.C. Evaluation of the impact of the Seaside health education conferences and the nutritional education training programs in the Oregon school systems, (Doctoral dissertation, University of Oregon) 1982 , summary from Oregon Department of Education, Salem, Oregon.)

Employee fitness: corporate philosophy for the 1980's. Athletic Purchasing and Facilities, 1980 , July.

Farquhar, J.W. How to stop smoking, Medical Self-Care, $1979 / 80$, no. $7,39-49 \ldots$

Feitler, F.C., \& Tokar, E. Getting a handle on teacher stress: how bad is the problem?. Educational Leadership, $1982 ., 39,456-458$.

Ferguson, M. The aquarian conspiracy. Los Angeles: J.P. Tarcher, Ind., 1980 .

Frost Valley YMCA, Inc. Building wellness lifestyles, administrator's guide. Montelair, N.J., 1980 .

Gaasholt, M. Self formulating study groups: an incentive approach to staff development in Denmark. Program Development Assistance System, Seattle: University of Washington, 1980 .

Jacobs, P. The impact of stress on our bodies. Planning for Health, 1982 , no. $4,1-2$.

Jennings, C., \& Tager, M.J. Good health is good busitiess. Medical Self-Care, 1981 , no. 13 .

Jetti, M., Campbell, J., Mangeon, J., \& Routhier, R. The Canadian home fitness test as a predictor of aerobic activity. CMA Journal, 1976, April, 80-82.

Kansas Department of Health and Environment. Add p.l.u.s. to your life. Topeka: 1978 .

Kaplan, B.H., Cassel, J.C., Gore, \& Susan. Social support and health, Medical Care, $1977,15,47-59$.

King, K. Selected behavioral strategies for the health educator. Health Education, 1982, 13, 35-37. 
Langlie, J.K. Social Networks, Journal of Health and Social Behavior, 1977,18 (3), 244-260.

Medical Datamation. Health hazards. Bellevue, Ohio: 1976.

Metress, E. Library research in health education. Health . Education, $1982,13,19-22$.

Miles, L., \& Stubblefield, H.W. Learning groups in training and education. Small Group Behavior, 1982, 13 , (3) $311-320$.

Naisbitt, J. Megatrends. New York: Warner Books, Inc., 1982 .

Nash, J.D., \& Ormiston, L.H. Taking charge of your weight and well-being. Palo Alto: Bull Publishing Company, 1978 .

Parkinson, R.S., \& Associates. Managing health promotion in the workplace. Palo Alto: Mayfield Publishing Company, 1982 .

Passwater, G.D. The development of an instrument to assess Oregon high school students nutrition knowledge. (Doctoral dissertation, Oregon State University, University Microfilm International, 1980,41 (014), 116)

Peters, K. In America, corporate fitness is an idea whose time is now. Runner's World, 1981, April, 55-57.

Reissman, F: Self-care and seld-help: natural allites, Medical Self-Care, $1979 / 1980$, no. $7,16-19$.

Rubin, L. The in-service education of teachers, trends, processes, and prescriptions. Boston: Allyn and Bacon, Inc., 1978 .

Ryan, R.S., \& Travis, J.W. The wellness workbook. Berkley: Ten Speed Press, 1981.

Stevens, V.J. Increasing professional productivity while teaching full time: a case study in self-control. Teaching of Psychology, 1978, 5, (4), 203-205.

Stevens, V.J., \& Spurr, J. Increasing study time and controlling student guilt: a case study in self-management. The Behavior Therapist, $1978, \underline{3}$ (2), $17-18$.

Tacoma Public Schools. Choices for Wellness. Tacoma, Wa.: Box 1357,1980 . 
Tager, M.J., \& Goldberg, M.H. Managing the health of your company. Northwest Stock Guide, 1982, Spring, 12-14.

Tucker, J.B. A delicate balance. The Runner, September, $1982,88-90$.

U.S. Department of Agriculture and the U.S. DHEW. Nutrition and your health, dietary guidelines for Americans. Washington, D.C.: Office of Government and Public Affairs, USDA.

U.S. DHEW. A concurrent validation study of the NCHS general well-being schedule. Hyattsville, Md.: no (HRA) 78-1347. September, 1977.

U.S. DHEW. Healthy people. Washington, D.C.: U.S. Government Printing of ice, no. 79-55071 A, 1979 .

U.S. DHEW. Living wel1. Washington, D.C.: U.S. Government Printing Office, no. 80-50121, 1980 .

U.S. DHEW. Promoting health/preventing disease, objectives for the nation. Washington, D.C.: Fall, 1980.

Wangberg, E.G. Helping teachers cope with stress. Educational Leadership, $1982,39,452-454$.

Winer, B.J. Statistical principles in experimental design. New York: MeGraw-Hill Book Company, Inc. 1962. 
APPENDIX A

Awareness Inservice for

Gresham Wellness Program 
HELCOME TO GRESIIAK-BARLOH INSERVICE

September 28,1982

Today's program is designed to acquaint you with ways to improve your own health and the health of your students...and... to renew acquaintances among the 325 staff members of our district.

After lunch and listening to our keynote speaker, Len Tritsch, we invite you to visit the following displays and events in the gym:

\section{Exhibitors}

HOLIDAY PARK HOSPITAL - Stress materials - Mickey Clarizio

OREGON LUNG ASSOC. - JOseph Weller

MliCC - Recreation and classes - Johnnie Stokes

BLUE CROSS - Pamphlets and materials

AMERICAN HEART ASSOC. - MarCie Jeans

AMERICAN CANCER SOCIETY - Cathy ROWland

GRESHAM HOSPITAL - Nutrition - Jodie

DANCERCIZE - Judy Reynolds

AEROBIC DANCE - Barbara Nemenchek

JAZZERCIZE - Chris Noga

MINI TRAMPOLINE - Jeannie Burgess

OREGON DIABETES ASSOC.

\section{Main Stage Demonstrations}

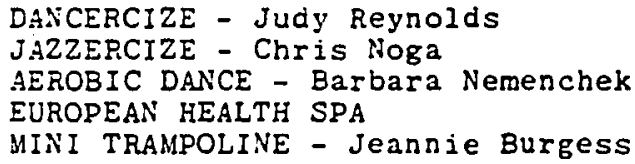

\section{Activity Stations}

MHCC FITNESS MEASUREMENT - Dr. Jeff Rheum P.A.H.C TESTING - Mr. Burden and Dr. Hall GRESHAM COURT CLUB - Scott Schaffer

EUROPEAN HEALTH SPA

HIGH SCHOOL TEAM

Sam \& Guy - Strength Measurement

Sue \& Gary - Fat Measurement

Sharon - Heart rate

Debile \& Kelly - Blood pressure

WELLNESS CLASS REGISTRATION - Wink Chilton Rose Lowes

Use this space to record
your measurements!
Your lung capacity
Skinfolds
Your heart rate
Your blood pressure
Strength of grip
Number of "curls"
Other:




\section{APPENDIX B}

Timelines for Gresham Wellness Program 


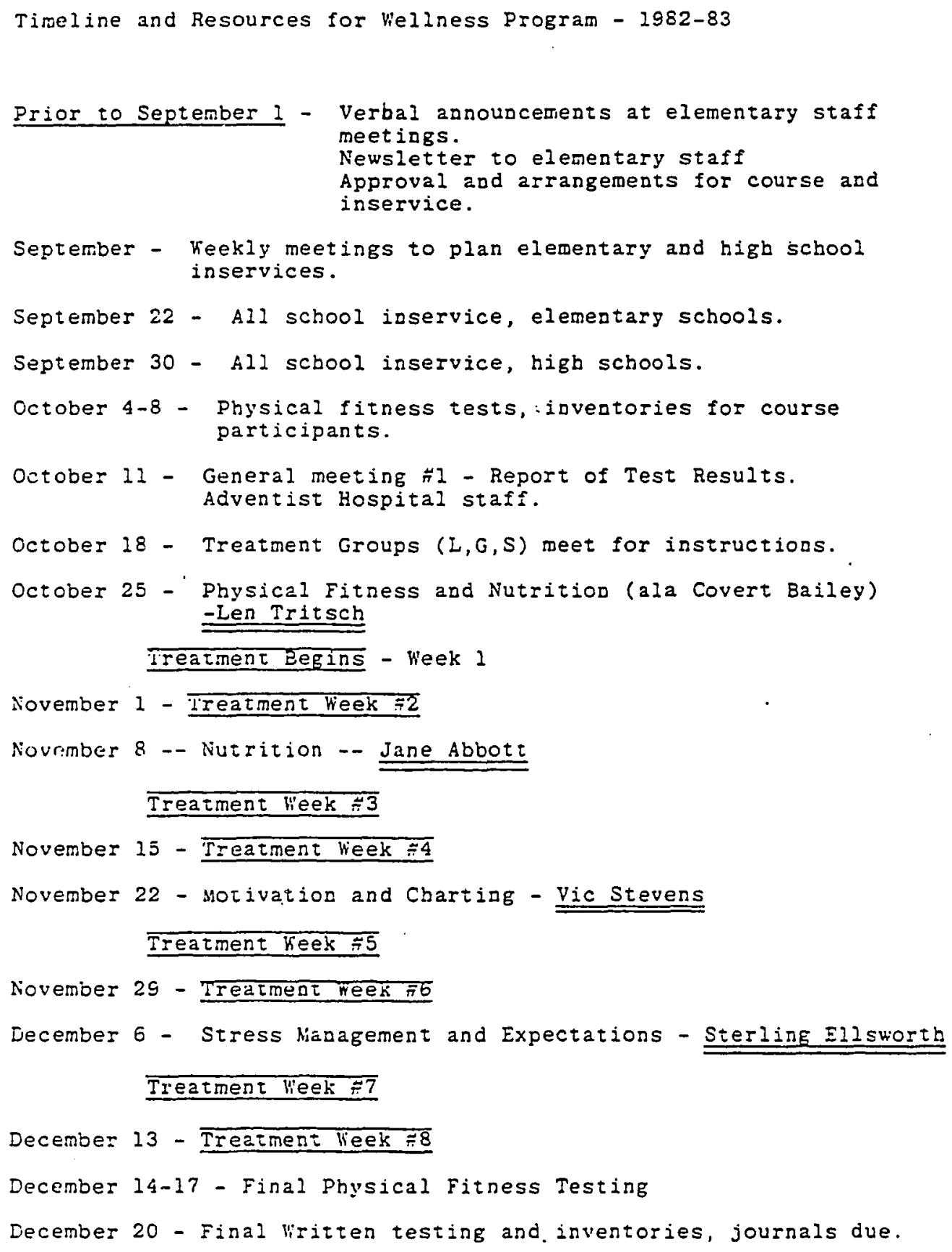




\section{APPENDIX C}

Directions for Developing a Plan for

Gresham Wellness Program 
WELLNESS FOR THE SCHOOL STAFF

Developing a Plan of Action

(For the eight week's program)

By October 17, 1982 you should have developed a plan of action that you can maintain through December 12 ( 8 weeks.)

Here are suggestions that we hope you will follow in developing your plan.

1. Goal setting and Planning

A. Road chapter 2 in Planning for Hellnoss, 1982.

This is the self-management format we will

follow in this course.

B. Two goals that we are requiring in the course are:

(1) aerobic exercising as described by Covert Bailey in Fit or Fat.

(2) following the U.S. DHEW dietary guidelines, handout copy provided.

(3) you should also set additional goals based on your own health needs. (Results of the tests and surveys will be returned on October 11.)

C. By the end of the course we hope you will have added goals in all five areas of wellness (Tager and Ardell, p. 7) but you can add some as you go along.

Complete a Contract (Tager and Ardel1, p. 185), extra copies provided, suitable for sharing with others.

2. Weekly planning and reporting.

A. As you do the suggested reading and hear the speakers you may add new goals and strategies. Therefore, you are encouraged to reaffirm your plan or alter it each Sunday and start new weeks on Mondays. Discuss any changes with your group or leader. (Do not fill out a new form.)

B. Keep any records or charts that you wish for yourself. Share these with your leader or group but you don' $t$ need to hand them in.

C. Submit a weekly report on the form provided on Monday's to your leader or to the project director. Please have the report signed by the leader or two other group members to show that it has been discussed. First report due is contract on October 18; then, regular report each Monday. 
3. Group Support

(a) A major contention of health promotion authorities is that people need the support of others to maintain a health program. Therefore, the class will test the value of two types of support; small group or teacherled. Each school will have one or the other organization.

(b) Teacher-led participants will submit goals and plans of action to their teacher who will reinforce successes and assist with changes. Weekly reports will be submitted to the teacher-leader. If possible, group meetings of those in a school should occur once a week.

(c) Self-help groups should meet once each week to share experiences, reinforce successes and alter plans, if necessary or desired. It is hoped these meetings can be right after or just before school for convenience of the individuals.

Summary of Course Activities

Oct. 4-10 - Set individual goals in exercise and nutrition.

Oct. II - Receive reports from PAMC, 4:45-7:00, Dexter McCarty School

Oct. 11-15 - Develop a plan of action, meet with small group or leader for approval.

Oct. I8 - Attend Victor Stevens presentation, 4:45-7:00; Submit contract to leader or project director.

Oct. 18- - Maintain 8 weeks program, meeting once each

Dec. I3 week with support group or leader; submit weekly report each Monday based on Monday through Sunday week.

Attend speakers and receive handouts and assignments on these dates.

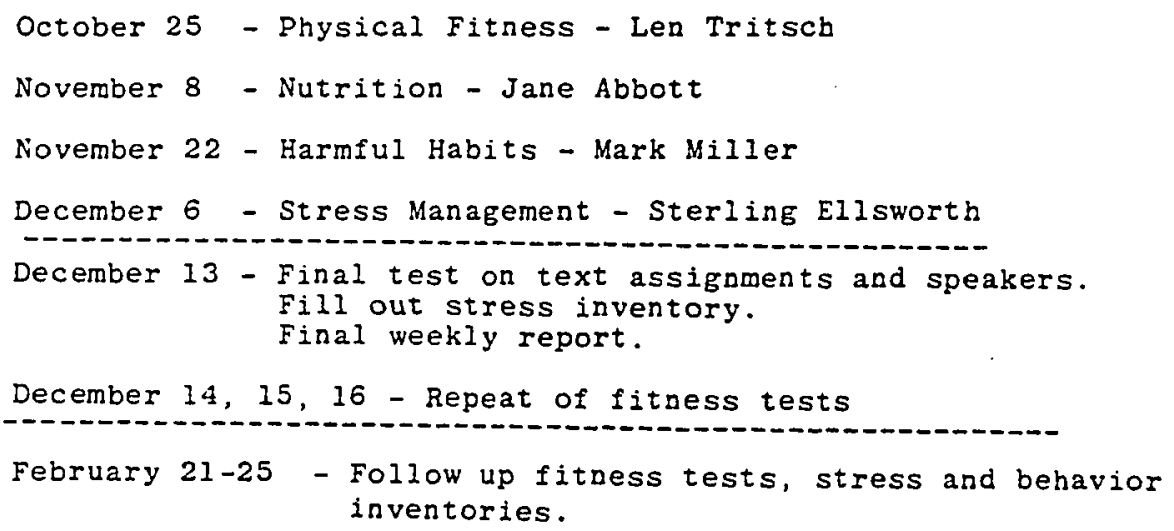


APPENDIX D

Sample Letter to Speakers for

Gresham Wellness Program 


\section{GRESHAM SCHOOL DISTRICTS 1333 NW EASTMAN \\ P.O. BOX 655 \\ GRESHAM, OR. 97030 \\ 661.3000 \\ James M. Jenkins. Superintendent}

October 27, 1982

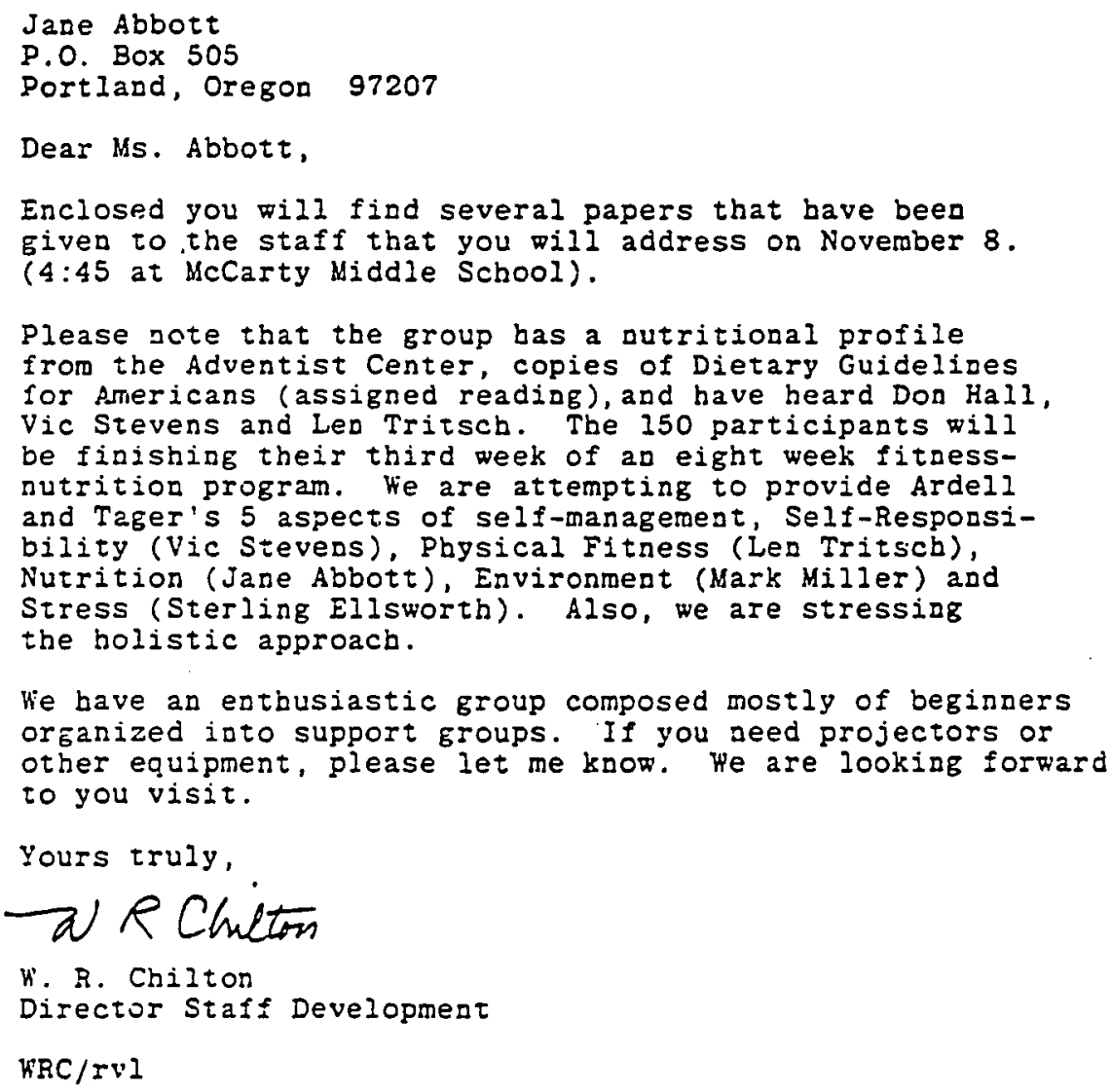




\section{APPENDIX E}

Health Behavior Weekly Reports for

Gresham Wellness Program 


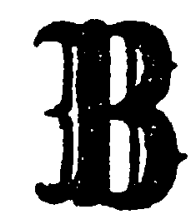

\section{Health Behavior Practices}

Physical Fitness

Name

$1,2,3$, Performed aerobic exercise achieving, but not exceeding your personal target heart rate for 20 minutes or more.

\begin{tabular}{llllll}
0 & 3 & 6 & 9 & 12 & 15 \\
\hline none one day & two days & three days & four days five days
\end{tabular}

Name type of exercise: aerobic dancing, walking, jogging, other:

4. Performed stretching and flexibility exercises especially before any vigorous exercise.

\begin{tabular}{llllll}
0 & 1 & 2 & 3 & 4 & 5 \\
\hline none & one day & two days & three days & four days & five days
\end{tabular}

5. Performed strength-building or endurance exercises (such as sit-ups, leg lifts, push-ups or other, according to personal need).

\begin{tabular}{llllll}
0 & $!$ & 2 & 3 & 4 & 5 \\
\hline none & one day & two days & three days & four days & five days
\end{tabular}

\section{Nutritional Practices}

\begin{tabular}{llllll}
0 & 1 & 2 & 3 & 4 & 5 \\
\hline two days or less & three days & four days & five days & six days & every day
\end{tabular}

6. Ate good breakfast

7. Ate a variety of foods each day; such as, fruits and vegetables, wholegrain breads and cereals, lean meats, dairy products, dry peas and beans and nuts and seeds.

8. Limited the amount of saturated fat and cholestorol (fat on meat, eggs, butter, cream shortenings and 1 iver).

9. Limited the amount of salt by cooking with small amounts, not adding salt at the table and avoiding saity snacks.

10. Limited the intake of sugar (candy, soft drinks, desserts or adding sugar to cereal). 
Stress Management (use same scale with 11-i4)

\begin{tabular}{llllll}
0 & $!$ & 2 & 3 & 4 & 5 \\
\hline none & one day & two days & three days & four days five days
\end{tabular}

11. Found enjoyment and satisfaction in your job.

12. Participated in relaxing time activities such as: sports, walks, dancing, reading or aerobic exercise.

13. Discussed days events or any stressful matters with friends, family members or associates.

14. Found a quiet time of one-half hour or more to meditate, reflect, or practice special exercises such as breathing, guided imagery or meditation.

Harmful Habits

15. Didn't Smoke

\begin{tabular}{llllll}
0 & $?$ & 2 & 3 & 4 & 5 \\
\hline more than & iess than & fewer than & fewer than & fewer than not at all \\
$1 \mathrm{pack} /$ day & one pack/day & $15 \mathrm{cig} / \mathrm{day}$ & $10 \mathrm{cig} / \mathrm{day}$ & $5 \mathrm{cig} / \mathrm{day}$ &
\end{tabular}

16. Limited drinking to two drinks or less per day

$\begin{array}{llllll}0 & 1 & 2 & 3 & 4 & 5 \\ \begin{array}{l}2 \text { days } \\ \text { or less }\end{array} & 3 \text { days } & \dot{4} \text { days } & 5 \text { days } & \dot{6} \text { days } & \text { every day }\end{array}$

Use the same scale for 17-20

\begin{tabular}{llllll}
0 & $!$ & $?$ & $?$ & 4 & 5 \\
\hline not at all & seldom & infrequently & is time & usually & all the time
\end{tabular}

17. Avoided use of drugs (including sleeping pills, cafferine, tranquilizers) except as specifically prescribed for a short duration.

18. Fastened safety belts and asked other passengers in your car to do the same.

\section{Self Responsfbility}

19. Recorded health behavior on charts or checklists or notes.

20. Rewarded yourself for achieving goals as stated (or making significant progress toward goals). 
Major Barriers this week

to maintaining progress

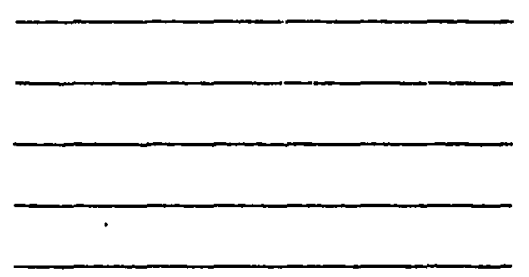

Major help this week to

maintaining program

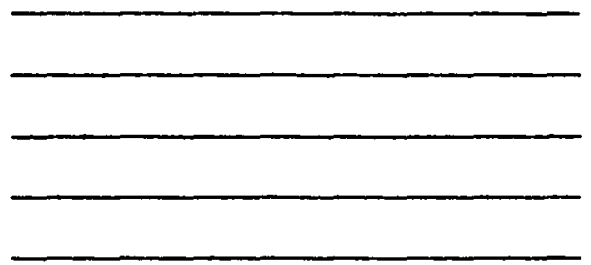

Support from other people

(if any) came from: 


\section{APPENDIX F}

Sample Letter to Participants of the

Gresham Wellness Program

$\cdots$ 
TO: Kellness class members

FRON: Wink Chilton, $R \mathcal{N}$

DATE: November 15,1982

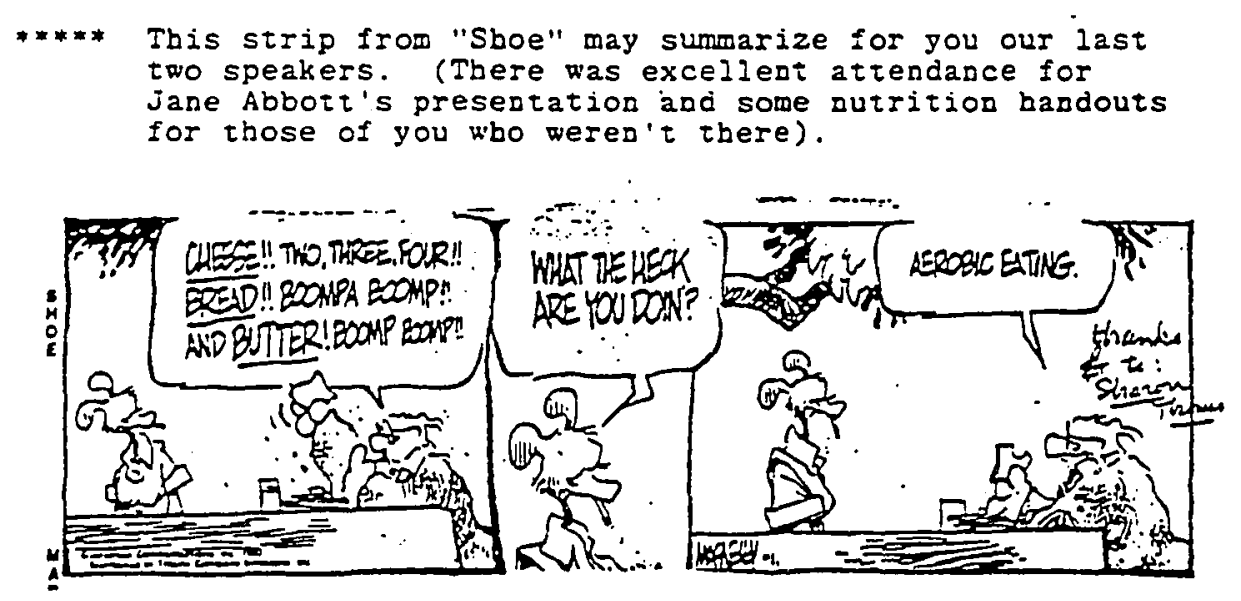

**** Available to you for small group meetings (or individually) are audio tapes of Jane's presentation and VTR of Covert Bailey - the autbor of Fit or Fat; call Rose Lowes.

***** Nark Miller will speak on November 22 as scheduled. ( $4: 45$, McCarty Commons). Fe is reputed to be 2 "bard-bitting" speaker who is straight-forward about use of drugs of all kiads including caffeine and alcobol.

***** If you have not seat in Report $\div 4$, please do so. Ninety percent of reports were in on time last week. Thank You! Aitendance is close to 150 members per session. Everywhere people are exercising, talking about autrition, and attempting to reduce stress. Fe are doing well! Four more weeks urtil we measure the resulis. 
APPENDIX G

Consent for Experimental Use of Data Gresham Wellness Program 
Consent for pre-, post, and follow-up testing

I understand that the physical fitness tests, nutritional intake inventory, General Well-Being questionnaire, and weekly reports of health practiçes will be used in a research project that will test the effectiveness of the program.

I understand that I will-receive a copy of the analyses of my personal data and that the project director will have a copy which he will keep in confidence. No names will be used in any published study. I will share'information with teachers and other class participants only as I choose to do so.

Signature

Date 